\title{
The Chinese geng clausal comparative
}

\author{
Chen-Sheng Luther Liu \\ Department of Foreign Languages and Literatures, National Chiao Tung University, \\ 1001 Ta Hsueh Road, Hsinchu 300, Taiwan
}

Received 15 January 2009; received in revised form 24 September 2009; accepted 28 September 2009

Available online 31 October 2009

\begin{abstract}
Based on the syntax and semantics of the Chinese geng 'GENG' clausal comparative, I first argue that Chinese does have degree comparison in syntax, contra the claim made by Kennedy (2005, 2007), and Lin (2009). I then discuss two further issues raised by the geng 'GENG' clausal comparative: first, to show how the geng 'GENG' clausal comparative fits into a larger system of Chinese comparatives, I dichotomize Chinese comparatives into presupposition and non-presupposition comparatives. Second, I argued that the Degree Abstraction Parameter proposed by Beck et al. (2004), though being empirically challenged by the Chinese geng 'GENG' clausal comparative, can be maintained if languages involving degree comparison in syntax are further divided into two types depending on how the degree variable is bound (Kennedy, 2007).
\end{abstract}

(C) 2009 Elsevier B.V. All rights reserved.

Keywords: Clausal comparatives; Degree comparison; Degree intervals; Degree points; Individual comparison; Movement versus non-movement parameter in degree abstraction; Phrasal comparatives

\section{Introduction}

Through studying the syntax and semantics of the Chinese comparative like (1c) (henceforth the Chinese geng 'GENG' clausal comparative), in which two difference degree intervals ((A) the difference between the degree value of Zhangsan's happiness and the contextually determined standard degree value of happiness; and (B) the difference between the degree value of Lisi's happiness and the contextually determined standard degree value of happiness) are compared, I claim that Chinese does have degree comparison in the syntax, contra Kennedy (2005, 2007), Xiang (2005), Erlewine (2007), and Lin (2009). ${ }^{1}$

\footnotetext{
E-mail address: csliu@faculty.nctu.edu.tw.

${ }^{1}$ To make the presentation smooth and not digress from the main theme, I simply assume the morpheme hen 'HEN' is a degree adverb, instead of specifying whether it is the overt form of the positive morpheme or an intensifier marker, unless it is necessary (Kennedy, 2005; Liu, 2010). I will also use GENG to represent the degree adverb geng, which is better glossed as 'even more' in this paper. Abbreviations used in this paper are: ASP: aspect marker, CL: classifier, DE: the verbal suffix or the marker for modifying phrases like genitive phrases, relative clauses, and noun complement clauses, and SFP: sentence final particle.
} 
(1) a. Zhangsan bi Lisi kaixin.

Zhangsan than Lisi happy

'Zhangsan is happier than Lisi.'

b. Zhangsan (jintian) (zai jia li) bi Lisi (zuotian) (zai xuexiao) geng kaixin.

Zhangsan today at home inside than Lisi yesterday at school GENG happy

'Zhangsan (today) is even happier (at home) than Lisi was (in school)

(yesterday), and both of them are happy.'

c. Zhangsan hen kaixin, Lisi geng kaixin.

Zhangsan HEN happy Lisi GENG happy

'Zhangsan is very happy, and Lisi is even happier than he is, and both of them are happy.'

d. Zhangsan geng kaixin.

Zhangsan GENG happy

'Zhangsan is even happier than somebody is, and both Zhangsan and that person are happy.'

Based on my interval-based analysis of the syntax and semantics of the Chinese geng 'GENG' clausal comparative, two further issues are discussed. First, to show how the Chinese geng 'GENG' clausal comparative fits into a larger system of Chinese comparatives, I assume that Chinese has a covert comparative morpheme (i.e., gerg) and the marker $b i$ 'than' simply functions like the English than; I go on to dichotomize Chinese comparatives into presupposition comparatives like (1b-d) on the one hand and non-presupposition comparatives like (1a) on the other, using the occurrence of the comparative morpheme geng 'GENG' (henceforth geng 'GENG') as criterion. $^{2}$ Second, although the Degree Abstraction Parameter proposed by Beck et al. (2004) is empirically challenged by the Chinese geng 'GENG' clausal comparative, this parameter still can be maintained if languages involving degree comparison in syntax are further divided into two types depending on how the degree variable is bound.

The organization of this paper is as follows. I shall start section 2 by discussing the syntactic and semantic properties of the Chinese geng 'GENG' clausal comparative, and end it by pointing out what questions this construction raises for the current syntactic and semantic theories of comparatives. In section 3, I first introduce as preliminary Kennedy's (2001a) interval-based account for the semantics of comparatives, and then an interval-based analysis of the semantics of the Chinese geng 'GENG' clausal comparative is proposed. Pushing this further, a new way of classifying Chinese comparatives is suggested in section 4, and the question of how to accommodate the impact on Beck et al.'s (2004) Degree Abstraction Parameter from the Chinese geng 'GENG' clausal comparative is discussed in section 5. Finally, the conclusion is reached in section 6.

\section{The syntax and semantics of the Chinese geng clausal comparative}

In this section, I discuss the syntactic and semantic properties of the Chinese geng 'GENG' clausal comparative from the following three perspectives: the semantics and syntax of the morpheme geng 'GENG', comparison of deviation and divergence, and degree comparison in syntax.

\footnotetext{
${ }^{2}$ Because of space limitations, I will not discuss two other types of Chinese comparatives, as shown by (i)-(ii):

(i) Zhangsan gao (Lisi)*(wu-gongfen).

Zhangsan tall Lisi five-centimeter

'Zhangsan is five centimeters taller than Lisi.'

(ii) Zhangsan gao-guo *(Lisi) (wu-gongfen).

Zhangsan tall-pass Lisi five-centimeter

'Zhangsan is five centimeters taller than Lisi.'

Please see Liu (2007) for discussion.
} 


\subsection{The semantics and syntax of the morpheme geng}

Studies on Chinese $b i$ 'than' comparatives, including Xiang (2005), Erlewine (2007), and Lin (2009), assume that the morpheme $b i$ 'than' not only has the function of English than but also has the function of the English comparative morpheme -er. For instance, according to Lin (2009:20), the morpheme $b i$ 'than', as in (1b), is a dyadic comparative degree head that might take one or more than one (individual, time or location) argument, and the whole DegP-shell headed by the degree word $b i$ 'than' is an adjunct adjoined to the predicate of comparison. In addition, the morpheme $b i$ 'than', with a denotation like (2a), behaves like the English comparative morpheme -er. So, example (1b) has a syntactic structure like (2b) under Lin's (2009) analysis.

(2) a. $\|\mathrm{bi}\|=(\lambda \mathrm{l})^{\mathrm{i}}(\lambda \mathrm{i})^{\mathrm{j}}(\lambda \mathrm{w})^{\mathrm{k}} \lambda \mathrm{x} \lambda \mathrm{P}_{<\mathrm{d},<(\mathrm{l}),<(\mathrm{i}),<(\mathrm{e}),<\mathrm{e}, \mathrm{l}>>>>}\left(\lambda \mathrm{l}^{\prime}\right)^{\mathrm{i}}\left(\lambda \mathrm{i}^{\prime}\right)^{\mathrm{j}}(\lambda \mathrm{z})^{\mathrm{k}} \lambda \mathrm{y}$

$\left[1_{\max } \mathrm{d}\left[\mathrm{P}(\mathrm{d})\left(\mathrm{l}^{\prime}\right)\left(\mathrm{i}^{\prime}\right)(\mathrm{z})(\mathrm{y})\right]>1_{\max } \mathrm{d}[\mathrm{P}(\mathrm{d})(\mathrm{l})(\mathrm{i})(\mathrm{w})(\mathrm{x})]\right]$

b. [S Zhangsan [AP [NP jintian] [AP [PP Zai jia li] [AP [DegP bi [DegP $_{\mathrm{NP}} \mathrm{Lisi}$ ]

[Deg' [Deg $\mathbf{t}_{\mathbf{i}}$ ] [DegP [NP Zuotian] [Deg' [Deg $\mathbf{t}_{\mathrm{i}}$ [PP at xuexiao] geng [AP kaixin]]]]]]]]].

Lin (2009), like other previous studies on Chinese comparatives, does not discuss the morpheme geng 'GENG', as in (1b), leaving its syntactic and semantic properties unclear under his analysis. However, examples like (1c,d), which involve comparison but do not contain the morpheme $b i$ 'than', imply that the morpheme geng 'GENG' should have a semantic function like that of the English comparative morpheme -er. Besides, both the semantic interpretation of $(1 b-d)$ and the fact that $(3 a, b)$ are true if and only if both Zhangsan and Lisi are tall indicate that the morpheme geng 'GENG' presupposes that the properties predicated of the compared 'objects' are true in the absolute sense.

(3) a. *Zhangsan bi Lisi geng gao ma? Dui a! Zhangsan bi Lisi geng

Zhangsan than Lisi GENG tall SFP Right SFP Zhangan than Lisi GENG

gao, danshi liang-ge dou bu gao.

tall but two-CL all not tall

'*Is Zhangsan even taller than Lisi is? Yes! Zhangsan is even taller than

Lisi is but both of them are not tall.'

b. Yaoshi Zhangsan bi Lisi geng gao dehua, ta jiu keyi lai.

If Zhangan than Lisi GENG tall SFP he then can come

'If Zhangsan is even taller than Lisi is and both of them are tall, then

Zhangsan is admitted to come here.'

Added to these, as (1b) and (1d) further indicate, it is not necessary for the degree adverb geng 'GENG' to correlatively occur with a degree adverb, for instance hen 'HEN'. (See footnote (15) for the further discussion on (1d)). Hence, the morpheme geng 'GENG', as one anonymous reviewer suggests to me, must be an independent morpheme. ${ }^{3}$

\footnotetext{
${ }^{3}$ Based on the following two facts, I argue that example (1c) should not be treated as the reduced form of a bi 'than' comparative like (i).

(i) Zhangsan hen kaixin, Lisi bi Zhangsan geng kaixin.

Zhangsan HEN happy Lisi than Zhangsan GENG happy

'Zhangsan is very happy, and Lisi is even happier than Zhangsan.'

First, under the following scenario, example (ii), a Chinese geng 'GENG' clausal comparative, can be felicitously interpreted, but example (iii), which involves a construction like (i), cannot.
}

(ii) Suiran Zhangsan-de fenshu hen gao, danshi wo renwei Lisi-de geng gao. Although Zhangsan-DE score HEN high but I think Lisi-DE GENG high 'Although Zhangsan's score is (very) high, I think that Lisi's is even higher.' 
For these reasons, I analyze (1c) as a multi-clausal sentence rather than a correlative construction (i.e., a correlative comparative) because examples like (1c) show the following properties of the Chinese multi-clausal sentence listed by Liu et al. (2004:863-864), and Xing (2004:191-193): (A) Clauses contained in a multi-clausal sentence are connected to each other in interpretation in order to express the meaning of the whole sentence completely. As I have argued, the morpheme geng 'GENG', having a semantic function like that of the English comparative morpheme -er, denotes a greater-than relation (e.g., $x$ is greater than $y$ along some dimension). In a Chinese geng 'GENG' clausal comparative like (1c), the standard of comparison (i.e., the difference between the degree value of Zhangsan's happiness and the contextually determined standard degree value of happiness), being an argument of the morpheme geng 'GENG', is syntactically realized as the first clause of the multi-clausal sentence (i.e., Zhangsan hen kaixin 'Zhangsan HEN happy'), which is semantically connected to the second clause (i.e., Lisi geng kaixin 'Lisi GENG happy'), which provides the other argument (i.e., the other difference degree interval) for the morpheme geng 'GENG'. In other words, the full meaning of the whole sentence can only be expressed completely by having these two clauses connected to each other in meaning. (B) Neither of the two clauses involved is contained in the other. (C) Like the clauses contained in a multi-clausal sentence, the clauses contained in (1c) can be separated from each other by a short pause. ${ }^{4}$

(iii) Suiran Zhangsan-de fenshu hen gao, danshi wo renwei Lisi-de fenshubi Zhangsan-de geng gao. Although Zhangsan-DE score very high but I think Lisi-DE score than Zhangsan-DE GENG high 'Although Zhangsan's score is very high, but I think Lisi's is even higher than Zhangan's.'

Suppose Zhangsan attended the entrance examination of medical school last year and Lisi this year. The score of Zhangsan is 530 points and the lowest enrollment score last year was 515 points. The score of Lisi is 520 points and the lowest enrollment score this year is 490 points. So, both Zhangsan's score and Lisi's are high because each of them has their score significantly higher than the (contextually determined) standard of comparison (i.e., the lowest enrollment score). (See footnote (12) for the details.) The contrast in felicitousness between (ii) and (iii) under the scenario above implies that what are compared in example (ii) are the difference between Zhangsan's score and last year's lowest enrollment score (i.e., 15 points) and that between Lisi's score and this year's lowest enrollment score (i.e., 30 points); however, what are compared in (iii) are Zhangsan's score (i.e., 530 points) and Lisi's score (i.e., 520 points). Hence, if example (1c) can be treated as the reduced form of a bi 'than' comparative like (i), then we would expect example (iii) to be felicitous under the scenario above, contrary to fact. Second, a geng 'GENG' clausal comparative like (iv) does not have a $b i$ 'than' comparative counterpart, as the contrast between (iv) and (v) illustrates.

(iv) Zhe-duo hua, hua hen hong, yezi geng lü.

This-CL flower flower HEN red leaf GENG green

'As for this flower, the flower is very red, but the leaf is even greener than the flower is red.'

(v) *Zhe-duo hua, hua hen hong, yezi bi hua geng lü.

This-CL flower flower HEN red leaf than flower GENG green

${ }^{4}$ Similarly, in a Chinese comparative like (i), the compared object $y$ (i.e., the standard of comparison) is syntactically realized as the $b i$ 'than' phrase bi Lisi 'than Lisi' and adjoined to the predicate geng gao 'GENG tall'. This extended predicate then forms a complete sentence with the other argument of the morpheme geng 'GENG', namely the subject NP Zhangsan, to have the meaning completely expressed.

(i) Zhangsan [[bi Lisi] [geng gao]].

Zhangsan than Lisi GENG tall

'Zhangsan is even taller than Lisi, and both of them are tall.'

However, one might say that example (1c) can be analyzed as a sequence consisting of two independent sentences because the two clauses contained inside can be uttered by different speakers in a dialogue, as shown below.

(ii) A: Zhangsan hen kaixin.

Zhangsan HEN happy

'Zhangsan is very happy.'

B: Lisi geng kaixin.

Lisi GENG happy

'Lisi is even happier.'

This way of reasoning, at first sight, sounds convincing, but it is not without problem because it offers no way to prevent us from saying that the two clauses involved in the following dialogue are also two independent sentences.

(iii) A: Mama hui chufa Xiaoming ma?

Mother will punish Xiaoming SFP

'Will Xiaoming's mother punish him?'

B: Yaoshi ta bu tinghua dehua.

If he not obedient SFP

'If he (i.e., Xiaoming) is disobedient, (...).'

Although both (iiiA) and (iiiB) can be uttered by different speakers in a dialogue, no one would say (iiiB) can form an independent sentence by itself because (iiiB), being a subordinate clause, can never occur as an independent sentence by itself. 
As Xing $(2001: 345-363,2004)$ further points out, the Chinese geng 'GENG' clausal comparative consists of two or more clauses which can be combined together by coordinators, for example budan 'but', danshi 'but' and erqie 'and', or (prepositional) subordinators like lian 'even', guran 'although' or yaoshi if, as sentences in (4) illustrate.

(4) a. Zhangsan, budan yanjing hen yuan, bizi hen ting, erduo geng da.

Zhangsan not-only eye HEN round noose very erect ear GENG big

'As for Zhangsan, not only his eyes are round, but his nose also stands erectly, and his ears are

even bigger than his eyes are round and his nose stands erectly.'

b. Zhangsan, lian zou lu dou hen kunnan, paobu geng bu-keneng.

Zhangsan even walk road all HEN difficult run GENG impossible

'It is very difficult for Zhangsan to walk. So, it is even more impossible for him to run than

it is difficult for him to walk.'

c. Qian guran hen zhongyao, jiankang geng zhongyao.

Money no-doubt HEN important health GENG important

'Although money is important, health is even more important to you than money is.'

d. Yaoshi Zhangsan hen gao dehua, Lisi jiu geng gao.

If Zhangan HEN tall SFP Lisi then GENG tall

'If Zhangsan is tall, then Lisi is even taller than Zhangsan is.'

Semantically, the last clause of the Chinese geng 'GENG' clausal comparative has to contain a degree phrase headed by the degree adverb geng 'GENG', which might have gengjia 'GENG-ADD' as alternate. This degree phrase functions to provide the 'comparee' degree with which the 'standard degree of comparison' provided by the degree phrase headed by the degree adverb like hen 'HEN' in the other clause (or the other clauses if the whole sentence consists of more than two clauses) is compared. For example, in (4a) the degree of roundness of Zhangsan's eyes denoted by the degree phrase hen yuan 'HEN round' in the first clause plus the degree of erection of Zhangsan's nose denoted by the degree phrase hen ting 'HEN erect' in the second clause functions as the 'standard degree of comparison' with which the 'comparee' degree (i.e., the size of Zhangsan's ears) denoted by the degree phrase headed by the degree adverb geng 'GENG' (i.e., geng da 'GENG big') is compared. For convenience of exposition, in the rest of this paper I call the clause involving the degree phrase that denotes the 'standard degree of comparison' the standard clause and the clause containing the degree adverb geng 'GENG' the 'comparee' clause.

In addition to this characteristic, the syntactic and semantic properties about the relations among the clauses contained in a geng 'GENG' clausal comparative still include: the order between the clauses involved cannot be switches, as shown by the contrast between (1c) and (5a), it is not necessary for the standard NP to have the same grammatical function as the comparee NP (e.g., in (5b) the comparee NP is the object NP geng duo ren 'GENG many people' while the standard NP is the subject NP hen duo ren 'HEN many people'); and it is not necessary for the predicates involved to be antonymous or to show a positive-negative polarity, as shown by $(5 \mathrm{a}-\mathrm{c})$, respectively.

(5) a. *Lisi geng kaixin, Zhangsan hen kaixin.

Lisi GENG happy Zhangsan HEN happy

b. Zuotian [NP hen duo ren] lai wo jia, jintian wo pai [NP geng

Yesterday HEN many people come I home today I send GENG

duo ren] qü ni jia.

many people go you home

'Yesterday, many people came to my home, but today I send even more people to yours.' 
c. Zhe-duo hua, budan hua hen hong, yezi geng lü.

This-CL flower not-only flower HEN red, leaf GENG green

'As for this flower, the flower is very red, but the leaf is even greener than the flower is red.'

These characteristics work together to exclude the possibility of analyzing the Chinese geng "GENG" clausal comparatives as conjoined comparatives, as defined by Stassen $(1985: 44){ }^{5}$

Besides, whenever the two (or more) degree-denoting elements in the Chinese geng 'GENG' clausal comparative are not directly dominated by the clauses further directly dominated by the whole construction, all the degree adverbs involved must be overtly realized and, more importantly, the coordinator danshi 'but' is obligatorily required, as the contrast between $(6)$ and $(7 a, b)$ shows.

(6)

[[standard clause Zhangsan (hen) gao], (danshi) [comparee clause Lisi geng gao]].

Zhangsan HEN tall but Lisi GENG tall

'Zhangsan is very tall, but Lisi is even taller.'

(7) a. [[Zhangsan *(hen) gao], *(danshi) [wo renwei [Lisi geng gao]]].

Zhangsan HEN tall but I think Lisi GENG tall

'Zhangsan is very tall, but I think that Lisi is even taller than Zhangsan is.'

b. [[[[Zhangsan *(hen) gao] de shuofa] guran mei cuo], *(danshi) [Lisi geng gao]].

Zhangsan HEN tall DE statement of-course not wrong but Lisi GENG tall

'The statement that Zhangsan is very tall of course is correct, but Lisi is even taller than Zhangsan is.'

I shall argue that the coordinator danshi 'but' in examples like $(7 \mathrm{a}, \mathrm{b})$ functions to help retain and intensify the comparison relation between the two 'degrees' in the Chinese geng 'GENG' clausal comparatives. Semantically, the coordinator danshi 'but' presupposes a contrast relation between the two conjuncts connected by it. In the Chinese geng 'GENG' clausal comparative, the two difference degrees 'denoted' by the two corresponding degree adverbs are compared with each other. Whenever these two degree-denoting elements are not directly dominated by the clauses that are further directly dominated by the whole construction, it becomes difficult for one to 'capture' the comparison relation between these two degree-denoting elements (i.e., the degree adverbs). Since the notion of contrast can be considered a special type of comparison, the coordinator danshi 'but' in this instance functions as the last resort to cooperate with the overt realization of the degree terms involved to rescue the comparison relation between these two degree adverbs. Thus, not only the coordinator danshi 'but' is obligatorily required but the degree term also has to be overtly realized.

Another important property of the morpheme geng 'GENG' in the Chinese geng 'GENG' clausal comparative is: although the degree adverb geng 'GENG' heading the degree phrase that provides the 'comparee degree' is obligatorily required in the Chinese geng 'GENG' clausal comparative, the degree adverb that functions to provide the

\footnotetext{
${ }^{5}$ Stassen (1985:44) imbues the conjoined comparative with the following characteristics: first, it consists of two structurally independent clauses: one containing the comparee NP, whereas the other the standard NP. Second, the two clauses in question show a structural parallelism, as the grammatical function of the comparee NP in one of the clauses is reduplicated by the grammatical function of the standard NP in the other clause (i.e., it is a type of derived-case comparatives). Third, the comparative predicates involved either form an antonymous pair or exhibit a positive-negative polarity.
} 
'standard degree of comparison' (e.g., hen 'HEN') can be omitted from the standard clause without affecting the grammaticality of the sentence, as (8) shows. ${ }^{6,7}$

(8) Zhangsan (hen) gao, Lisi *(geng) gao.

\section{Zhangsan HEN tall Lisi GENG tall}

'Zhangsan is (very) tall, and Lisi is even taller than Zhangsan is.'

However, I simply assume that, in examples like (8), the optionality of the degree adverb in the standard clause is an epi-phenomenon, and making such an assumption in fact does not significantly impact on the main theme I eventually argue for in this paper. My assumption is simply based on the semantic interpretation of examples like (8). As the semantic interpretation of (8) indicates, although Zhangsan's height exceeds the contextually determined standard height of human beings in a significant difference, the difference in which Lisi's height exceeds the contextually determined standard height of human beings further exceeds that significant difference. This semantic property shown by a Chinese geng 'GENG' clausal comparative like (8) serves as evidence for us to assume that the standard clause of the Chinese geng 'GENG' clausal comparative provides a context where the occurrence of a covert degree term (perhaps the covert positive morpheme) is licensed because semantically degree terms, as Kennedy and McNally (2005:367) suggest, function to regulate the relationship between the degree of the property denoted by an adjective that modifies an entity (or a concept) and the (inherent or contextually determined) standard degree value on the scale denoted by that property. ${ }^{8}$

In contrast with the optionality of the degree adverb in the standard clause, the obligatoriness of the degree adverb geng 'GENG' might result from the labeling function it plays. Since the degree adverb geng 'GENG' in examples like (8) occurs as a marker to label the whole construction as a geng 'GENG' clausal comparative, the omission of the degree adverb geng 'GENG' from the comparee clause is prohibited. (See footnote (16) for further discussion.)

More significant here is that not all degree adverbs can occur in the standard clause of the Chinese geng 'GENG' clausal comparative, as shown by the contrast between $(9 a-d)$ and $(10 a, b)$.

(9) a. *Zhangsan gengjia/hai gao, Lisi geng gao. (strong geng type)

Zhangsan GENG/even tall Lisi GENG tall

b. *Zhangsan zui/ding gao, Lisi geng gao. (strong zui type)

Zhangsan most/extremely tall Lisi GENG tall

c. *Zhangsan bijiao/jiao gao, Lisi geng gao. (weak zui type)

Zhangsan more/more tall Lisi GENG tall

(10) a. Zhangsan shaowei/shaoshao/lüewei gao yi-dian, Lisi geng gao. (weak geng type)

Zhangsan a-little-bit/a-little-bit/slightly tall a-little-bit Lisi GENG tall

'Zhangsan is a little bit tall; however, Lisi is even taller than Zhangsan is.'

b. Zhangsan hen/xiangdang/feichang/youdian gao, Lisi geng gao.

(hen type)

Zhangsan very/rather/extremely/a-little-bit tall Lisi GENG tall

'Zhangsan is very/rather/extremely/a little bit tall; however, Lisi is even taller than Zhangsan is.'

\footnotetext{
${ }^{6}$ See example (6)-(7a,b) and discussion there for the optionality of degree adverbs in the standard clause.

${ }^{7}$ Example (i), in contrast with the English comparative deletion construction like (ii), further indicates that no comparative deletion applies to the Chinese geng 'GENG' clausal comparative.

(i) Zhangsan hen gao, Lisi geng gao.

Zhangsan very tall Lisi GENG tall

'Zhangsan is very tall, and Lisi is even taller than Zhangsan is.'

(ii) John is taller than [CP Bill is [AP

${ }^{8}$ Kennedy and McNally (2005:367) characterize the meanings of degree morphemes (terms) in terms of the template in (i).

(i) $\quad[[\operatorname{Deg}(\mathrm{P})]]=\lambda G \lambda x \cdot \exists d[\mathrm{R}(d) \wedge G(d)(x)]$

What distinguishes different degree morphemes from each other is the value of $\mathrm{R}-$ the specific restriction (or the restriction relation) they impose on the adjective's degree argument.
} 
c. Suiran Zhangsan shifen/wanfen/yichang/ji/jiduan

Although Zhangsan rather/extremely/abnormally/extremely/extremely

jinzhang, danshi Lisi geng jinzhang. (hen type)

anxious, but Lisi GENG anxious

'Although Zhangsan is rather/extremely/abnormally/extremely/extremely anxious,

Lisi is even more anxious than Zhangsan is.'

d. Ni shuo Zhangsan tai/guo gao, danshi Lisi bu shi geng gao ma? Na!

You say Zhangsan too/exceed tall but Lisi not is GENG tall SFP PRT

weishenme Lisi keyi, danshi Zhangsan que bu keyi canjia bisai. (hen type)

why Lisi can but Zhangsan surprisingly not can attend contest

'You say that Zhangsan is too tall. However, isn't Lisi even taller than Zhangsan is?

Why is Lisi allowed to attend the contest but Zhangsan is surprisingly not?'

At this point, we immediately encounter the question of what kinds of degree adverbs can occur in the standard clause of the Chinese geng 'GENG' clausal comparative. According to Ma (1992), Lu and Ma (1999) and Zhang (2002), Chinese degree adverbs can be classified as three types, depending on their distribution in different types of constructions, including the $b i$ 'than' comparative, the bi-qilai 'compare-qilai/compared with' construction, and the non-comparative construction, and each type further consists of a strong and a weak group. To state it more clearly, the geng type (i.e., the GENG type) includes those that can occur only in the $b i$ 'than' comparative and the bi-qilai 'compare-qilai/compared with' construction, the hen type (i.e., the HEN type) consists of those that can only occur in the bi-qilai 'compare-qilai/compared with' construction and the non-comparative constructions, and the zui type (i.e., the most type) contains only those occurring in the superlative, as illustrated by examples in (11)-(14), respectively.

(11) a. Zhangsan bi Lisi gengjia/gengwei/yuefa/yuejia/hai nuli. (strong group)

Zhangsan compare Lisi more/more/more/more/even diligent

'Zhangsan is even more diligent than Lisi is.'

b. Zhangsan bi Lisi shaowei/shao/shaoshao/duoshao/

Zhangsan compare Lisi slightly/rather/a-little-bit/somewhat/

lüewei/lüelüe yonggong yi-dian. (weak group)

slightly/slightly hard-working a-little-bit

'Zhangsan works slightly/rather/a little bit harder than Lisi does.'

(12) a. Gen Zhangsan bi-qilai, Lisi gengjia/gengwei/yuefa/yuejia/hai

With Zhangsan compare-qilai Lisi more/more/more/more/even

nuli yi-xie. (strong group)

diligent a-little-bit

'Compared with Zhangsan, Lisi is even a little bit more diligent.' 
b. Gen Zhangsan bi-qilai, Lisi shaowei/shao/shaoshao/duoshao/

With Zhangsan compare-qilai Lisi slightly/rather/a-little-bit/somewhat

lüewei/lüelüe yonggong yi-dian. (weak group)

slightly/slightly hard-working a-little-bit

'Compared with Zhangsan, Lisi works slightly/rather/a little bit harder.'

(13) a. (Gen Zhangsan bi-qilai), Lisi hen/ting/shifen/?wanfen/

With Zhangsan compare-qilai Lisi very/rather/very/extremely/

feichang/yichang/ji/jiduan shengqi. (strong group)

abnormally/too/extremely/extremely angry

'(Compared with Zhangsan), Lisi is very/rather/extremely/abnormally/

extremely/extremely angry.'

b. (Gen Zhangsan bi-qilai), Lisi youdian/youxie shengqi. (weak group)

With Zhangsan compare-qilai Lisi a-little-bit/slightly angry

'(Compared with Zhangsan), Lisi is a little bit angry.'

(14) a. Zhangsan zui/zuiwei/ding congming. (strong group)

Zhangsan most/most/extremely smart

'Zhangsan is the smartest.'

b. Zhangsan bijiao/jiao/jiaowei congming. (weak group)

Zhangsan relatively/rather/rather smart

'Zhangsan is relatively/rather smarter.'

As I have argued, one of the semantic properties of the degree adverb geng 'GENG' that occurs in the Chinese geng 'GENG' clausal comparative is to require the difference between the degree of 'X-ness' denoted by the 'comparee' element and the contextually determined standard degree of ' $\mathrm{X}$-ness' in the comparee clause to be greater than the difference between the degree of 'X-ness (or Y-ness)' denoted by the 'standard' element and the contextually determined standard degree of 'X-ness (or Y-ness)' in the standard clause. For example, in (8) the difference between Lisi's height and the contextually determined standard height of human beings must be greater than the difference between Zhangsan's height and the contextually determined standard height of human beings. So, it is this specific property of geng 'GENG' that excludes the zui 'most' type of degree adverbs, either the strong or the weak group, from occurring in the standard clause of the Chinese geng 'GENG' clausal comparative. Besides, this specific semantic property of the degree adverb geng 'GENG' also excludes degree adverbs that belong to the strong group of the geng 'GENG' type from occurring in the standard clause of the Chinese geng 'GENG' clausal comparative because the degree adverb geng 'GENG' is also a member of the strong group of the geng 'GENG' type of degree adverbs.

\subsection{Comparison of deviation and divergence}

As I have pointed out, what are compared in the Chinese geng 'GENG' clausal comparative are (A) the difference between the degree of 'X-ness' denoted by the 'comparee' element and the contextually determined standard degree of 'X-ness' in the comparee clause, and (B) the difference between the degree of 'X-ness (or Yness)' denoted by the 'standard' element and the contextually determined standard degree of 'X-ness (or Y-ness)' in the standard clause. Additionally, it is not necessary for the predicates involved to be antonymous or show a positive-negative polarity. Given these observations, I expect that a Chinese geng 'GENG' clausal comparative formed out of a 'positive' 
and 'negative' pair of adjectives would differ from its English counterpart in not showing the cross-polar anomaly. The facts bear out this expectation, as the contrast between (15a,b) and (16)-(17) illustrates (Hale, 1970; Bierwisch, 1987; Kennedy, 2001a:36).

(15) a. ?Alice is shorter than Carmen is tall.

b. ?New York is dirtier than Chicago is clean.

(16) a. Zhao Min, pifu hen bai, toufa geng hei.

Zhao Min skin HEN white hair GENG black

'The skin of Zhao Min is white, and her hair is even blacker than her skin is white.'

b. Nei jiahuo suiran shou hen chang, danshi tui geng duan. Suoyi zheng-ge

That guy though hand HEN long but leg GENG short So whole-CL

ren kan-qilai jiu shi hen qiguai.

person see-qilai then is very strange

'Although the hands of that guy are (very) long, but his legs are even

shorter than his hands are long. So, he looks strange.'

c. Suiran women-de zhongfeng hen gao, danshi women-de houwei que

Although we-DE center HEN tall but we-DE guard but

geng ai, suoyi women haishi shu-le qiu.

GENG short so we still lose-ASP ball

'Although the center of our team is very tall, our guard is even shorter than

their guard is. So, we still lose the game.'

d. Suiran women-de zhongfeng pao-de hen kuai, danshi women-de houwei

Although we-DE center run-DE HEN fast but we-DE guard

que pao-de geng man, suoyi women haishi shu-le qiu.

But run-DE GENG slow so we still lose-ASP ball

'Although the center of our team runs very fast, our guard runs even more

slowly than their guard does. So, we still lose the game.'

(17) a. Ni-de shoubiao huai le. Miao zhen hen kuai, fen zhen geng man.

Your watch out-of-order SFP Second hand HEN fast minute hand GENG slow

'Your watch is out of order. The second hand is fast, but the minute hand is

even more slowly than the second hand is fast.'

b. $\mathrm{Ni}$ zhe-bu gangqin zouyin le. Re/D hen di, La/A geng gao.

You this-CL piano off-key SPF Re HEN flat A GENG sharp

'Your piano is off-key. Re/D is flat, and La/A is even sharper than Re/D is flat.'

More interestingly, Chinese geng 'GENG' clausal comparatives constructed out of the 'positive' and 'negative' pair of adjectives can be further divided into two types, depending on their semantic interpretations: one is represented by cases like (16a-d) and the other by the examples in (17). The former involve a comparison of deviation (henceforth COD), which compares the relative extents to which the two objects deviate from some standard value associated with the adjective. For instance, the meaning of (16a) can be paraphrased as in (18). 
(18) The degree to which the blackness of Zhao Min's hair exceeds the contextually determined standard of blackness of female hair is greater than the degree to which the whiteness of Zhao Min's skin exceeds the contextually determined standard of whiteness of female skin.

This type of geng 'GENG' clausal comparative further shows the specific properties delineated in (A) through (D): (A) In contrast with the meaning of the COD type of Chinese geng 'GENG' clausal comparatives, standard $b i$ 'than' comparatives compare the absolute projections of two objects on a scale at the semantic level, as shown in (19):

(19) Zhe-zuo shangu de shendu bi shi-ceng lou de gaodu haiyao da.

This-CL valley DE depth than ten-story building DE height even large

'The depth of this valley is greater than the height of a ten-story building.

(B) Unlike standard comparatives, Chinese COD-like geng 'GENG' clausal comparatives entail that the properties predicated of the compared 'objects' are true in the absolute sense. This is in a way similar to what Kennedy (2001a) points out for the English COD comparative, as is verified by the contrast below.

(20) a. Nei jiahuo suiran shou hen chang, danshi tui geng duan.

That guy though hand HEN long but leg GENG short

'Although the hands of that guy are (very) long, but his legs are even

shorter than his hands are long.'

b. *Na jiahuo suiran shou hen chang, danshi tui geng duan. Buguo shou han

That guy though hand HEN long but leg GENG short But hand and

tui dou bu chang.

leg all not long.

'*Although the hands of that guy are (very) long, but his legs are even

shorter than his hands are long. However, neither his legs nor hands are long.'

More precisely, the fact that (20a) entails that the hands of that guy are long and his legs are short makes (20b) contradictory but (20a) not. This property is clearly related to the interpretation of Chinese COD-like geng 'GENG' clausal comparatives. Since the truth of an expression of the form ' $x$ is $\varphi$ ' is determined by whether the degree to which $x$ is $\varphi$ exceeds an appropriate standard value, the fact that comparison deviation constructions compare the degrees to which two objects exceed their respective standard values derives the observed entailment patterns naturally.

(C) Interpretations of this type of Chinese geng 'GENG' clausal comparative are not restricted to comparatives formed out of the antonymous pairs of adjectives (Kennedy, 2001a:43).

(21) Zhe-dong dalou, gaodu hen gao, kuandu geng kuan.

This-CL building height HEN tall width GENG wide

'This building is very tall, and it is even wider than it is tall.'

(D) In Chinese geng 'GENG' clausal comparatives constructed out of antonymous pairs of adjectives, the COD interpretation is the only interpretation available. For example, (20a) has only the reading that the degree to which the length of that guy's legs falls behind the standard length of human legs is greater than the degree to which the length of that guy's hands exceeds the standard length of human hands.

The second type of Chinese geng 'GENG' clausal comparative that is formed out of adjectives of opposite polarity but not semantically anomalous is represented by examples like $(17 \mathrm{a}, \mathrm{b})$, which involve a comparison of divergence. 
Although the pairs of adjectives in (17a,b) are clearly opposites in some sense, (17a,b) are not anomalous only on a very specific interpretation: one in which the adjectives measure divergence from some common reference point (which, as (22) shows, need not be the same for the two objects) - a conventionalized value (e.g., on time for (17a)) - in different directions.

(22) Suiran ni-de jiepaiqi hen kuai, danshi ni-de gangqin Re/D que geng di. Although you-DE metronome HEN fast but you-DE piano Re/D but GENG flat

'Although your metronome is very fast, your piano is off-key and Re/D is even

flatter than your metronome is fast.'

Hence, what is unique about comparisons of divergence and deviation is that both types of comparatives compare the degrees to which two objects deviate from some reference point (which need not be the same for the two objects) - a conventionalized value in the former case and a contextually determined standard value in the latter; whereas, standard comparatives, for example (19), compare the absolute measures of two objects on a scale at the semantic level. That is, what are compared in constructions involving a comparison of deviation or a comparison of divergence are two difference degree intervals rather than two (absolute) degree points (or intervals). ${ }^{9}$

\subsection{Degree comparison in syntax}

As Beck et al. (2004) argue, the availability of degree abstraction would allow the generation of attributive degree binding structures and comparative subdeletion structures. So, the grammaticality of (23a), which involves attributive comparison, and the grammaticality of (23b), where a comparison between quantities of different sorts of stuff is involved, imply that the Chinese geng 'GENG' clausal comparative allows binding of degree variables in the syntax.

(23) a. Zhangsan mai-le hen duo shu, Lisi mai-le geng duo shu.

Zhangsan buy-ASP HEN many book Lisi buy-ASP GENG many book

'Zhangsan bought many books, and Lisi bought even more books.'

b. Zhe-duo hua, hua hen hong, yezi geng lü.

This-CL flower flower HEN red leaf GENG green

'As for this flower, the flower is red, but the leaf is even greener.'

\footnotetext{
${ }^{9}$ More noteworthy here, the Chinese geng 'GENG' clausal comparatives can co-occur with a dynamic verbal predicate, as (i)-(ii) illustrate.

(i) Zhe-suo xuexiao, laoshi shou ren liwu, xiaozhang geng na ren hongbao.

This-CL school teacher receive people gift president GENG take people cash-gift (a bribe)

'As for this school, the president is more corrupt than the teacher is because the

teacher takes graft, but the president takes cash-gift.'

(ii) Tamen liang, yi-ge da-le ren, ling yi-ge geng sha-le ren.

They both one-CL hit-ASP people other one-CL GENG kill-ASP people

'As for those two bad guys, one affected the victim more seriously than the other did because the former killed the victim while the other hit the victim.'

Examples of this kind make the Chinese geng 'GENG' clausal comparatives so peculiar in the following two aspects: first, the degree adverb geng 'more' in the Chinese geng 'GENG' clausal comparatives differs from other degree adverbs (e.g., hen 'HEN') in that the former can modify a dynamic event predicate while the latter, for example hen 'HEN', cannot. Second, this kind of examples raises the question of what are compared in this type of geng 'GENG' clausal comparatives if a dynamic verb such as $d a$ 'hit' or sha 'kill' is considered as being non-gradable. However interesting and significant this type of the Chinese geng 'GENG' clausal comparatives is, to keep the paper from being too lengthy, following one anonymous reviewer's suggestion, I defer considering this type of the Chinese geng 'GENG' clausal comparative here.
} 
However, the grammaticality of (24a), in which the comparee clause is embedded inside a syntactic island, as well as the grammaticality of (24b), which lacks the negative island effect, indicates that Beck et al.'s (2004) implication is empirically challenged by the Chinese geng 'GENG' clausal comparative.

(24) a. [s [NP [s Zhe-duo hua hen hong de] shuofa] guran mei cuo], danshi

This-CL flower HEN red DE statement of-course not wrong but

wo xiang zhidao [CP yezi shifou geng lü].

I want know leaf whether GENG green

'The statement that this flower is very red of course is true, but I wonder

whether the leaf is even greener.'

b. Zhangsan shuo meiyou ren kan-guo zhe-me gao de shu, danshi wo

Zhangsan say no people see-ASP this-way tall DE tree but I

zhidao Lisi kan-guo geng gao de shu.

know Lisi see-ASP GENG tall DE tree

'Zhangsan said that nobody saw a tree of that height, but I know that Lisi saw a tree even taller.'

In other words, the grammaticality of (23a,b) implies that the Chinese geng 'GENG' clausal comparative involves degree comparison and requires the degree variable involved to be bound. However, the insensitivity to the island effect shown by $(24 a, b)$ indicates that the degree variable involved should not be bound by a moved degree operator at the syntactic level.

Additionally, based on the semantic properties of the comparative morpheme geng 'GENG' that I have pointed out, the most proper translation for a Chinese geng 'GENG' clausal comparative like (25a) is (25b), in which the standard of comparison, namely the degree operator (i.e., Op) in [Spec, CP], must be syntactically local to the head of the comparative (i.e., blacker) (Williams, 1977; Hazout, 1995; Kennedy, 1999; Kennedy, 2001a,b).

(25) a. Zhao Min, pifu [DegP hen [AP bai]], toufa [DegP geng [AP hei]].

Zhao Min skin very white hair GENG black

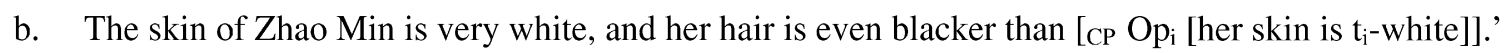

The degree value (i.e., the degree of whiteness) of the degree operator in (25b) then is further contextually specified by that of the predicate very white in the first clause of the translation. However, the ungrammaticality of (26) implies that, instead of using a $b i$ 'than' phrase as the Chinese counterpart of the English than phrase to introduce the standard of comparison, the Chinese geng 'GENG' clausal comparative directly uses the 'standard clause' (i.e., pifu hen bai 'skin very white') to introduce the standard of comparison. (See footnote (18) for discussion on the ungrammaticality of examples like (26)).

(26) *Zhao Min, pifu hen bai, toufa [bi [pifu hen bai] geng hei].

Zhao Min skin HEN white hair than skin HEN white GENG black

'The skin of Zhao Min is very white, and her hair is even blacker than her skin is white.'

However, in contrast to an English clausal comparative, which strictly requires the degree operator to be local to the head of the comparative at LF, the Chinese geng 'GENG' clausal comparative allows either the standard clause or the comparee clause to occur inside a syntactic island, as the contrast between (27a,b) and (28a,b) illustrates (Ross, 1967; Chomsky, 1977). 
(27) a. Michael has more scoring titles than [CP $\mathrm{Op}_{\mathrm{i}}\left[\mathrm{Kim}\right.$ says [CP Dennis plans to get $\mathrm{t}_{\mathrm{i}}$-tattoos]]].

b. *Michael has more scoring titles than $\left[\mathrm{CP}_{\mathrm{O}} \mathrm{Op}\right.$ [Dennis is [NP a guy [CP who has $\mathrm{t}_{\mathrm{i}}$-tattoos]]].

(28) a. Zhao Min, pifu [DegP hen [AP bai]], toufa [DegP geng [AP hei]].

Zhao Min skin HEN white hair GENG black

'The skin of Zhao Min is very white, and her hair is even blacker than her skin is white.'

b. [s Opp [NP [s Zhao Min pifu hen ${ }_{i}$ bai de] shuofa] guran mei cuo],

Zhao Min skin HEN white DE statement of-course not wrong

danshi wo xiang zhidao [CP toufa shifou geng hei].

but I wonder know hair whether GENG black

'The statement that the skin of Zhao Min is very white is absolutely true,

but I wonder whether her hair is even blacker than her skin is white.'

So in a Chinese geng 'GENG' clausal comparative, the standard of comparison seems not to be necessarily local to the 'head' of the comparative, for example geng hei 'GENG black' in (28b).

Before concluding this section, I briefly highlight the empirical and theoretical questions to the current syntactic and semantic analyses of comparatives raised by the Chinese geng 'GENG' clausal comparative. First, as I have pointed out, what are compared in the Chinese geng 'GENG' clausal comparative are two difference degree intervals rather than two degree points. So any analysis of the syntax and semantics of the Chinese geng 'GENG' clausal comparative must not only derive the difference reading naturally but also must account for the challenge to the pointbased analysis to the semantics of comparatives raised by this construction (Kennedy, 2001a; Schwarzschild and Wilkinson, 2002).

Second, besides the geng 'GENG' clausal comparative, Chinese still has a structurally simpler mono-clausal comparative like (1a), repeated as (29a), which differs from the geng 'GENG' clausal comparative like (29c) in syntax and semantics.

(29) a. [s Zhangsan [AP [PP bi Lisi] [AP kaixin]].

Zhangsan than Lisi happy
'Zhangsan is happier than Lisi.'

b. [s Zhangsan [AP [NP jintian] [AP [PP Zai jia li] [AP [DegP bi [DegP [NP Lisi]

Zhangsan today at home inside than Lisi

[Deg, [Deg $\mathrm{t}_{\mathrm{i}}$ ] [DegP [NP Zuotian] [Deg, [Deg $\mathrm{t}_{\mathrm{i}}$ ] [PP at xuexiao] geng [AP kaixin]]]]]]]]].

yesterday at school GENG happy

'Zhangsan (today) is even happier (at home) than Lisi was (in school)

(yesterday), and both of them are happy.'

c. Zhangsan hen kaixin, Lisi geng kaixin.

Zhangsan HEN happy Lisi GENG happy

'Zhangsan is very happy, and Lisi is even happier than he is, and both of them are happy.'

Many previous studies of Chinese comparatives not only group examples (29a,b) together as one type dubbed as the $b i$ 'than' comparative by using the occurrence of the marker $b i$ 'than' as criterion for classifying Chinese comparatives, but also analyze the marker $b i$ 'than' as a comparative morpheme (Chao, 1968; Fu, 1977; Li and Thompson, 1981; Tsao, 1989; Paul, 1993; Liu, 1996; Shi, 2001; Liu, 2004; Xiang, 2005; Erlewine, 2007; Xu, 2007; 
Lin, 2009). ${ }^{10}$ So whether the morpheme geng 'GENG' in the Chinese geng 'GENG' clausal comparative is the same as the one in (29b) immediately becomes a question I cannot evade. Additionally, as two anonymous reviewers remind me, it is not entirely innocuous if the question of how the structurally more complex geng 'GENG' clausal comparative fits into a larger system of Chinese comparatives is missed.

Third, although the Chinese geng 'GENG' clausal comparative allows the generation of attributive comparison and comparison between quantities of different sorts of stuff, this construction surprisingly does not show the island sensitivity effect as the English clausal comparative does. So, can the Degree Abstraction Parameter (i.e., a language \{does, does not $\}$ have binding of degree variables in the syntax) proposed by Beck et al. (2004:325) be maintained? If it can be, how can it be?

\section{The proposal}

I introduce as preliminary Kennedy's (2001a) interval-based analysis to the semantics of comparatives first, and then propose an interval-based analysis to the semantics of the Chinese geng 'GENG' clausal comparative. To forecast the main themes of my analysis: first, the morpheme geng 'GENG', being a comparative morpheme denoting a greater-than relation, takes two arguments and requires one of them to be greater than the other along some dimension. Second, the comparative morpheme geng 'GENG' presupposes that the properties predicated of the compared 'objects' must be true in the absolute sense. Third, the type of arguments that the comparative morpheme geng 'GENG' takes depends on whether the compared 'object' is introduced by the $b i$ 'than' phrase or the degree adverb contained in the standard clause of the Chinese geng 'GENG' clausal comparative. It is the degree adverb in the standard clause of the geng 'GENG' clausal comparative that provides a difference degree interval as the standard of comparison. This 'difference-degree-interval-like' standard of comparison further causes the comparative morpheme geng 'GENG' to require the other argument which it takes to be a difference degree interval.

\subsection{Preliminary: Kennedy (2001a)}

According to Hale (1970), Bierwisch (1987), and Kennedy (2001a:36), English comparatives constructed out of the 'positive' and 'negative' pair of adjectives like (30) are semantically anomalous, an anomaly referred to as the crosspolar anomaly.

?Alice is shorter than Carmen is tall.

The cross-polar anomaly, as Kennedy (2001a:37) argues, cannot be explained in terms of syntactic ill-formedness because the structurally identical examples of 'comparative subdeletion' (i.e., CSD) where both adjectives have the same polarity are perfectly well-formed, as shown in (31).

My watch is faster than yours is slow.

Given this, Kennedy (2001a:37) suggests that the factors underlying the cross-polar anomaly should involve an interaction of the semantics of positive and negative adjectives and the semantics of the comparative construction (Seuren, 1978; Ladusaw, 1986; Linebarger, 1980).

\footnotetext{
${ }^{10}$ This dichotomy is immediately challenged by the semantic distinction between (29a) and (29b): (29a) does not entail that both Zhangsan and Lisi are happy but (29b), which contains the morpheme geng 'GENG', does. Although this semantic distinction seems to imply that the occurrence of geng 'GENG' might be used as a criterion for classifying Chinese comparatives, the situation is not so straightforward. In particular, even though $(29 \mathrm{~b}, \mathrm{c})$ both contain the morpheme geng 'GENG', example (29b) still differs from (29c) in that what are compared at the semantic level in (29b) are two absolute degrees (or degree intervals) (i.e., the degree of Zhangsan's happiness and that of Lisi's happiness) but what are compared in (29c) are the difference between the degree value of Zhangsan's happiness and the contextually determined standard degree value of happiness and the difference between the degree value of Lisi's happiness and the contextually determined standard value of happiness.
} 
As Kennedy (2001a:37) points out, particularly significant here is that a large class of antonymous adjectives makes the relation in (32) valid, as shown by (33).

$x$ is more $\varphi_{\text {pos }}$ than $y$ if and only if $y$ is more $\varphi_{\text {neg }}$ than $x$.

Alice is shorter than Carmen if and only if Carmen is taller than Alice.

Within a model of point-based analysis to the semantics of gradable adjectives and comparatives, this fact, as Kennedy (2001a:38) argues, can be directly explained by adopting the following three natural assumptions. First, gradable adjectives are characterized as expressions that map objects to abstract representations of measurement (i.e., scales), which are sets of points (i.e., degrees) that are totally ordered along a dimension determined by the adjective (e.g., height, weight, ...) (Cresswell, 1976; Hellan, 1981; von Stechow, 1984; Rullmann, 1995).

Second, comparatives define ordering relations between degrees.

Third, assuming the point-based analysis to the semantics of gradable adjectives, antonymous pairs of adjectives such as tall and short map identical arguments onto the same degrees, but they introduce the opposite ordering relations. Namely, such pairs are duals: for all antonymous adjectives $\varphi_{\text {pos }}, \varphi_{\text {neg }}$ that map their arguments onto a shared scale $S$, and for all $d_{1}, d_{2} \in S$, the relation in (34) holds.

$$
d_{1}>\varphi_{\text {pos }} d_{2} \Leftrightarrow d_{2}>{ }_{\text {甲neg }} d_{1}
$$

Given these three assumptions, the truth condition of (32), for instance, can be paraphrased as in (35).

the degree to which Carmen is tall $>_{\text {tall }}$ the degree to which Alice is tall $\Leftrightarrow$ the degree to which Alice is short $>$ short the degree to which Carmen is short

Suppose degrees correspond to points in an ordered set, and positive and negative adjectives map their arguments onto the same degrees - an assumption necessary to explain the validity of constructions with the form in (32) - then (36) is equivalent to (37).

the degree to which Alice is short $>$ short the degree to which Carmen is tall

the degree to which Alice is short $>$ short the degree to which Carmen is short

This line of reasoning, as Kennedy (2001a:38) points out, happens to make the wrong prediction about the crosspolar anomaly because we would incorrectly predict that (30) is grammatical. So, the point-based analysis to the semantics of gradable adjectives and comparatives is challenged by cross-polar anomaly.

To account for cross-polar anomaly, Kennedy (2001a) proposes an interval-based analysis to the semantics of comparatives with the following two major assumptions. First, adopting Landman's (1991:110) definition of an interval for a linearly ordered set of points, Kennedy (2001a:52-57) analyzes degrees as intervals on a scale, and makes a structural distinction between two sorts of degrees: positive and negative degrees. Positive degrees (i.e., $P O S(S)$ ) are intervals that range from the lower end of a scale to some point, while negative degrees (i.e., $N E G(S)$ ) are intervals that range from some point to the upper end of a scale.

$$
\begin{array}{ll}
\text { a. } & \operatorname{POS}(S)=\left\{d \subseteq S \mid \exists p_{1} \in d \forall p_{2} \in S\left[p_{2} \leq p_{1} \rightarrow p_{2} \in d\right]\right\} \\
\text { b. } & N E G(S)=\left\{d \subseteq S \mid \exists p_{1} \in d \forall p_{2} \in S\left[p_{1} \leq p_{2} \rightarrow p_{2} \in d\right]\right\}
\end{array}
$$

In all of these, as Kennedy (2001a:53) argues, the result amounts to inferring that the positive and negative projections of an object $x$ on a scale $S$ are intervals in complementary distribution on the same scale, as the diagram in (39) shows.

$$
\mathrm{S}: 0-\operatorname{pos}_{s}(x)-\bullet-\operatorname{neg}_{s}(x) \rightarrow \infty
$$

The adjectival polarity, therefore, can be characterized as a difference in the ranges of the functions denoted by positive and negative adjectives: positive adjectives denote functions from individuals to positive degrees; negative adjectives denote functions from individuals to negative degrees. 
Kennedy (2001a:61) further argues that it is possible to identify the difference between any two degrees as the interval that is contained in one but not the other. Seen in this light, 'difference degrees', like positive degrees, correspond to finite closed intervals. Hence, what we have to do in interpreting difference comparatives, as Kennedy (2001a:61) suggests, is introduce a function that maps difference degrees onto degrees with minimal elements that correspond to the zero point of the scale in a structure-preserving way, as (40) shows.

$$
\begin{aligned}
& \text { [[ZERO }]]=\left\{<d_{1}, d_{2}>\mid\right. \\
& \text { (i) } \forall p_{1}, p_{2} \in d_{1}\left[p_{1}<p_{2} \rightarrow \exists p^{\prime}{ }_{1}, p^{\prime}{ }_{2} \in d_{2}\left[p^{\prime}{ }_{1}<p^{\prime}{ }_{2}\right]\right] \wedge \\
& \text { (ii) } \forall p^{\prime}{ }_{1}, p^{\prime}{ }_{2} \in d_{2}\left[p^{\prime}{ }_{1}<p^{\prime}{ }_{2} \rightarrow \exists p_{1}, p_{2} \in d_{1}\left[p_{1}<p_{2}\right]\right] \wedge \\
& \text { (iii) } \operatorname{MIN}\left(d_{2}\right)=\operatorname{MIN}(S)
\end{aligned}
$$

Thereby, a difference comparative with the form like (41a), with the measure phrase $12 \mathrm{~cm}$, can be assigned the interpretation in (41b).
a. $\quad$ Alice is $12 \mathrm{~cm}$ shorter than Carmen (is).
b. $\quad \operatorname{short}(a)>\operatorname{short}(c) \wedge \mathrm{ZERO}(\operatorname{short}(a)-\operatorname{short}(c)) \geq 12 \mathrm{~cm}$

As (41b) shows, the difference between the two negative degrees (i.e., $\operatorname{short}(a)$ and $\operatorname{short}(c)$ ) is a closed interval on the scale; therefore, a mapping to a degree in the set of degrees named by the measure phrase can be established by the ZERO function.

The second assumption Kennedy (2001a:44) makes in his interval-based account for cross-polar anomaly is as follows: comparatives are semantically well-formed only if they define ordering relations between the same sorts of degrees: between positive degrees, between negative degrees, or between degrees that measure divergence from a referent point.

On these assumptions, the cross-polar anomaly shown by examples like (30) can be explained naturally because an ordering relation, as Kennedy (2001a:58) suggests, requires its arguments to be elements of the same sort. However, in (30) the adjective in the main clause (i.e., short) is negative while the adjective in the than clause (i.e., tall) is positive; therefore, (30) is ill-formed. In a difference comparative like (41a), the difference between the two negative degrees, being a closed interval on the scale, belongs to the same kind of set as the degree denoted by $12 \mathrm{~cm}$ does; therefore, (41a) is well-formed. Thus, difference degrees, either between positive or negative degrees, can be mapped to degrees in the set of intervals that begin at the zero point of a scale. Hence, comparisons between such kind of derived degrees should be semantically well-formed because orderings between them can be defined.

\subsection{The semantics of the Chinese geng clausal comparative: an interval-based analysis}

Assuming Kennedy's (2001) interval-based analysis to the semantics of comparatives, in the following I first propose a preliminary analysis for the semantics of the comparative morpheme geng 'GENG' that will be further revised as I discuss how the Chinese geng 'GENG' clausal comparative fits into a larger system of Chinese comparatives. The main theme of the preliminary analysis is as follows: in the Chinese geng 'GENG' clausal comparative, the morpheme geng 'GENG', in addition to presupposing that the properties predicated of the compared objects are true in the absolute sense, is a comparative morpheme that takes two difference degree intervals as argument and requires one of them to be greater than the other along some dimension. ${ }^{11}$ For example, in the standard clause of (42), the degree adverb hen 'HEN' not only requires the degree interval denoted by the whiteness of Zhao Min's skin (i.e., white $(z m s)$ ) to be greater than the degree interval denoted by the contextually determined standard

\footnotetext{
${ }^{11}$ One anonymous reviewer wonders whether there is an argument here that we really need to compare difference degree intervals. The strongest evidence for the assumption that what are compared in the Chinese geng 'GENG' clausal comparative are two difference degree intervals comes from the fact that the Chinese geng 'GENG' clausal comparative, for example (i), does not show cross-polar anomaly.
}

(i) Zhao Min, pifu hen bai, toufa geng hei.

Zhao Min skin HEN white hair GENG black

'The skin of Zhao Min is white, but her hair is even blacker than her skin is white.'

If what are compared in (i) are not two difference degree intervals, then example (i) should be semantically anomalous, contrary to fact. 
degree value of whiteness of female skin (i.e., $\mathrm{d}_{s(\text { white })}$ ), but also requires the difference between these two degree intervals to be significant, as (43) shows (Graff, 2000; Kennedy, 2005, 2007; Liu, 2010). ${ }^{12}$

(42) Zhao Min, pifu hen bai, toufa geng hei.

Zhao Min skin HEN white hair GENG black

'The skin of Zhao Min is white, but her hair is even blacker than her skin is white.'

(43) white $(z m s)>\mathrm{d}_{s(\text { white })} \wedge \mathrm{ZERO}\left(\right.$ white $\left.(z m s)-\mathrm{d}_{s(\text { white })}\right)>0 \wedge \mathrm{ZERO}($ white $(z m s)-$

$\left.\mathrm{d}_{s(\text { white })}\right)$ is significant

Since the semantics of the degree morpheme hen 'HEN' requires that the difference degree interval between the degree interval denoted by the whiteness of Zhao Min's skin and that denoted by the contextually determined standard degree value of whiteness of female skin (i.e., ZERO $\left(\right.$ white $\left.(z m s)-\mathrm{d}_{s(\text { white })}\right)$ ) has to be significant, I further suggest that this 'difference degree interval' component of the semantics of the degree morpheme hen 'HEN' is highlighted and selected as the standard of comparison by the comparative morpheme geng 'GENG' in the Chinese geng 'GENG' clausal comparative at the syntactic level. The comparative morpheme geng 'GENG' in the comparee clause of (42) then requires the comparee clause to generate a difference degree interval that is greater than the one provided by the degree adverb hen 'HEN' contained in the standard clause as follows: the morpheme geng 'GENG' requires the comparee clause of (42) to generate a degree interval denoted by the blackness of Zhao Min's hair (i.e., black(zh))) first; next this degree interval is required to be greater than the degree interval denoted by the contextually determined standard degree value of blackness of female hair (i.e., $\mathrm{d}_{s(\text { black })}$ ); and the difference between these two degree intervals must be significant also, as (44) shows.

$$
\operatorname{black}(z m h)>\mathrm{d}_{s(\text { black })} \wedge \operatorname{ZERO}\left(\operatorname{black}(z m h)-\mathrm{d}_{s(\text { black })}\right)>0 \wedge \operatorname{ZERO}\left(\text { black }(z m h)-\mathrm{d}_{s(\text { black })}\right) \text { is significant }
$$

The comparative morpheme geng 'GENG', due to its comparison function, further requires the difference degree interval provided by the comparee clause to be greater than the difference degree interval provided by the degree adverb in the standard clause. So, example (42) can be assigned an interpretation like (45):

$$
\begin{aligned}
& \text { white }(z m s)>\mathrm{d}_{s(\text { white })} \wedge \mathrm{ZERO}\left(\text { white }(z m s)-\mathrm{d}_{s(\text { white })}\right)>0 \wedge \mathrm{ZERO}\left(\text { white }(z m s)-\mathrm{d}_{s(\text { white })}\right) \text { is significant } \wedge \\
& \operatorname{black}(z m h)>\mathrm{d}_{s(\text { black })} \wedge \mathrm{ZERO}\left(\text { black }(z m h)-\mathrm{d}_{\text {s(black })}\right)>0 \wedge \mathrm{ZERO}\left(\text { black }(z m h)-\mathrm{d}_{s(\text { black })}\right) \text { is significant } \wedge \\
& \operatorname{ZERO}\left(\operatorname{black}(z m h)-\mathrm{d}_{s(\text { black })}\right)>\operatorname{ZERO}\left(\text { white }(z m s)-\mathrm{d}_{s(\text { white })}\right)
\end{aligned}
$$

(45) has these properties: first, the ZERO function is invoked to compare two degree intervals. Second, both difference degree intervals are significant. Third, the difference degree interval provided by the comparee clause is greater than the one provided by the standard clause. Fourth, given the presupposition of the comparative morpheme geng 'GENG', the properties predicated of the compared 'objects' (i.e., the whiteness of Zhao Min's skin and the blackness of her hair) are true in the absolute sense.

Taking a line similar to Kennedy's (2001a) analysis to English clausal comparatives involving a comparison of divergence, I suggest that the Chinese geng 'GENG' clausal comparative that involves a comparison of divergence, for example (46), can be analyzed in the same way as I have done for the Chinese geng 'GENG' clausal comparative that involves a comparison of deviation. However, the two differ in one important aspect: the properties of comparatives involving a comparison of divergence suggest that adjectives in this type of comparatives map their arguments directly onto difference degrees because both members of the 'antonymous' pair, for example kuai 'fast' and man 'slow' in (46), accept measure phrases, as $(47 a, b)$ illustrate.

\footnotetext{
12 The requirement that in (42) the difference between the two degree intervals must be significant is clearly shown by the fact that example (i), which contains a predicative adjective modified by the degree adverb hen 'HEN', is unacceptable in scenario A (i.e., this rope is $15 \mathrm{~m}$ long, and that one is $14 \mathrm{~m}$ long), which involves a crisp judgment, but acceptable in scenarios B (i.e., this rope is $15 \mathrm{~m}$ long, and that one is $10 \mathrm{~m}$ long), which does not.

(i) Gen na-tiao shengzi bi-qilai, zhe-tiao hen chang.

With that-CL rope compare-qilai this-CL HEN long

'Compared with that rope, this one is very long.'
} 
(46) Ni-de shoubiao huai le. Miao zhen hen kuai,fen zhen geng man.

Your watch out-of-order SFP Second hand HEN fast minute hand GENG slow

'Your watch is out of order. The second hand is very fast, but the minute hand is

even slower than the second hand is fast.'

(47) a. Miao zhen kuai wu-miao.

Second hand fast five-second

'The second hand is five seconds fast.'

b. Fen zhen man shi-fenzhong.

Minute hand slow ten-minute

'The minute hand is ten minutes slow.'

Put more precisely, in example (46) and (47a,b), both the adjective kuai 'fast' and man 'slow' measure the degrees to which their arguments diverge from some arbitrary point (whatever counts as 'on time' in the context of utterance), as (48) shows.

$$
\text { time: } 0 \longrightarrow \text { [on time }] \longrightarrow \infty
$$

The acceptability of (46), therefore, can be accounted for by making an additional assumption that, on their difference interpretation, these adjectives (i.e., kuai 'fast' and man 'slow') include the ZERO function as part of their meaning. So, the logical representation of (46) is simply like a standard interpretation except for the addition of the ZERO function, which, by hypothesis, is built into each adjective's meaning, as shown by (49).

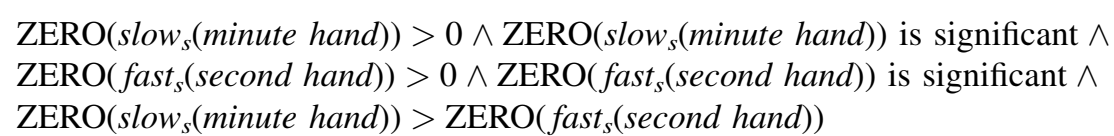

This analysis straightforwardly explains why an antonymous pair of adjectives in the Chinese geng 'GENG' clausal comparatives which involve a comparison of divergence fails to make valid the substitution instances of (32), repeated as (50), but the same does not happen in an ordinary comparative, as illustrated by the different uses of kuai 'fast' and man 'slow' in $(51 \mathrm{a}, \mathrm{b})$.

(50) $x$ is more $\varphi_{\text {pos }}$ than $y$ if and only if $y$ is more $\varphi_{\text {neg }}$ than $x$.

(51) a. *[Wo-de biao hen kuai, ni-de biao geng kuai] ruo-qie-weiruo [ni-de I-DE watch very fast you-DE watch GENG fast if-and-only-if you-DE

biao hen man, wo-de biao geng man].

watch very slow I-DE watch GENG slow

'*Your watch is even faster than mine is if and only if my watch is even slower than yours is.'

b. [Ni-de che bi wo-de che kuai] ruo-qie-weiruo [wo-de che bi

You-De car compare I-DE car fast if-and-only-if I-DE car compare

ni-de che man].

you-DE car slow

'Your car is faster than my car if and only if my car is slower than your car.' 
The reason why (51a) is false can be briefly described as follows: if both of our watches exceed the actual time but yours is farther ahead of it than mine is, then neither of these two watches is behind the actual time. So, (51a) is invalid.

Thus far, the main themes of my analysis of the geng 'GENG' clausal comparative like (42) and (46) can be summarized as follows: first, the morpheme geng 'GENG' is a comparative morpheme. Second, this comparative morpheme takes two difference degree intervals as arguments and requires one of them to be greater than the other along some dimension. Third, it is the degree adverb in the standard clause of the geng 'GENG' clausal comparative that provides the standard of comparison (i.e., the difference degree interval) at the syntactic level. Fourth, the comparative morpheme geng 'GENG' presupposes that the properties predicated of the compared 'objects' must are true in the absolute sense.

However, this analysis of the semantics of the comparative morpheme geng 'GENG', as I have already pointed out, is immediately challenged by the fact that the morpheme geng 'GENG' is also found in a $b i$ 'than' comparative like (29b), repeated as (52), if the marker bi 'than', as Lin (2009) suggests, is considered as a comparative morpheme.
Zhangsan (jintian) (zai jia
li)
bi Lisi (zuotian) (zai xuexiao) geng kaixin.
Zhangsan today at home inside than Lisi yesterday at school GENG happy
'Zhangsan (today) is even happier (at home) than Lisi was (in school) (yesterday), and both of them are happy.'

Moreover, two anonymous reviewers have reminded me that it is not entirely innocuous if the question of how the structurally more complex geng 'GENG' clausal comparative fits into a larger system of Chinese comparatives is missed.

\section{A new dichotomy of Chinese comparatives}

In this section, I propose that Chinese comparatives should be classified as the presupposition comparative on the one hand, and the non-presupposition comparative on the other by using the occurrence of the morpheme geng 'GENG' as criterion. Central to this proposal are the following assumptions: first, there is only one geng 'GENG' in Chinese and it is a comparative morpheme. The semantics of this comparative morpheme (the final version) are as follows: the comparative morpheme geng 'GENG', in addition to presupposing that the properties predicated of the compared objects must be true in the absolute sense, takes two arguments and requires one of them to be greater than the other along some dimension. The type of arguments that the comparative morpheme geng 'GENG' takes at the syntactic level depends on whether the compared 'object' is introduced by the $b i$ 'than' phrase or by the degree adverb contained in the standard clause of the geng 'GENG' clausal comparative. On one hand, the $b i$ 'than' phrase introduces (individual, time, or location) arguments for the comparative morpheme geng 'GENG', and these arguments are mapped onto absolute degree intervals at the semantic level by using Heim's (1985) direct analysis to phrasal comparatives (Lin, 2009). On the other hand, the degree adverb contained in the standard clause of the geng 'GENG' clausal comparative introduces a difference degree interval as argument for the comparative morpheme geng 'GENG' in the geng 'GENG' clausal comparative.

Second, Chinese has a covert comparative morpheme (i.e., gersg), which occurs only in a comparative construction not containing the comparative morpheme geng 'GENG' ${ }^{13}$ The covert comparative morpheme geng differs from the comparative morpheme geng 'GENG' in that (A) it does not presuppose that the properties predicated of the compared 'objects' must be true in the absolute sense; and (B) it takes two individuals (or times or locations) as arguments and requires one of them to be greater than the other along some dimension. In other words, I analyze Chinese comparatives

\footnotetext{
${ }^{13}$ As noted in footnote (2), the types of Chinese comparatives like (i) and (ii) there, repeated as (i)-(ii) here, are not discussed in this paper.

(i) Zhangsan gao (Lisi) *(wu-gongfen).

Zhangsan tall Lisi five-centimeter

'Zhangsan is five centimeters taller than Lisi.'

(ii) Zhangsan gao-guo *(Lisi) (wu-gongfen).

Zhangsan tall-pass Lisi five-centimeter

'Zhangsan is five centimeters taller than Lisi.'

My assumption about the existence of the covert comparative morpheme geng does not apply to examples like (i)-(ii).
} 
containing this covert comparative morpheme as phrasal comparatives and use Heim's (1985) 'direct analysis' to interpret them.

Third, instead of assuming that the morpheme $b i$ 'than' not only has the function of English than but also has the function of the English comparative morpheme -er, I suggest that the morpheme $b i$ 'than' simply functions like the English than in introducing the compared 'object' only.

Fourth, I assume a revised dyadic argument comparison analysis to the Chinese $b i$ 'than' comparatives. (See Lin (2009) for discussion of other analyses on the Chinese $b i$ 'than' comparative, including Tsao (1989), Paul (1993), Liu (1996), Xiang (2005), and Erlewine (2007).) According to Lin (2009), a Chinese bi 'than' comparative like (53) is analyzed as a dyadic argument comparative construction with a structure like (54), in which the marker $b i$ 'than', being a dyadic argument comparative degree head, carries the function of the English than as well as that of the English comparative morpheme -er.

(53) Zhangsan zuotian zai xuexiao bi Lisi jintian zai jia li kaixin.

Zhangsan yesterday at school than Lisi today at home inside happy

'Yesterday Zhangsan was happier at school than Lisi is at home today.'

(54) [s Zhangsan [AP [NP zuotain] [AP [PP Zai xuexiao] [AP [DegP bi [DegP [NP Lisi] [Deg'

[Deg $\mathrm{t}_{\mathrm{i}}$ ] [DegP [NP jintian] [Deg' [Deg $\mathrm{t}_{\mathrm{i}}$ [PP at jia li] [AP kaixin]]]]]]]]]].

Syntactically the morpheme $b i$ 'than' which takes three arguments (i.e., the individual argument Lisi, the time argument jintian 'today', and the location argument zai jia li 'at home inside') and must be flanked by constituents of the same type; the whole DegP-shell headed by the marker $b i$ 'than' is an adjunct adjoined to the predicate of comparison. Semantically, the morpheme $b i$ 'than' has a denotation like (55), a semantic function similar to that of the English comparative morpheme -er.

$$
\begin{aligned}
& \| \text { bi } \|=(\lambda l)^{\mathrm{i}}(\lambda \mathrm{i})^{\mathrm{j}}(\lambda \mathrm{w})^{\mathrm{k}} \lambda x \lambda \mathrm{P}_{<\mathrm{d},<(\mathrm{l}),<(\mathrm{i}),<(e),<e, t>>>>>}\left(\lambda \mathrm{l}^{\prime}\right)^{\mathrm{i}}\left(\lambda \mathrm{i}^{\prime}\right)^{\mathrm{j}}(\lambda \mathrm{z})^{\mathrm{k}} \lambda \mathrm{y} \\
& {\left[\mathrm{l}_{\max } \mathrm{d}\left[\mathrm{P}(\mathrm{d})\left(\mathrm{l}^{\prime}\right)\left(\mathrm{i}^{\prime}\right)(\mathrm{z})(\mathrm{y})\right]>\mathrm{\iota}_{\max } \mathrm{d}[\mathrm{P}(\mathrm{d})(\mathrm{l})(\mathrm{i})(\mathrm{w})(\mathrm{x})]\right]}
\end{aligned}
$$

So (53) is analyzed as a (multiple)-phrasal comparative by using Heim's (1985) direct analysis to interpret it.

Here, I basically follow Lin's (2009) analysis to the Chinese $b i$ 'than' comparative except that I suggest that the marker $b i$ 'than' is a dyadic argument preposition head which simply functions as the English than to introduce the compared 'object' only. It is the covert comparative morpheme geng that carries the function of the English comparative morpheme er. ${ }^{14}$

With these assumptions, I suggest that Chinese comparatives like (56a,b) belong to the same type, namely the presupposition comparative, though (56b) contains the marker $b i$ 'than' while (56a) does not.

(56) a. Zhangsan hen kaixin, Lisi geng kaixin.

Zhangsan HEN happy Lisi GENG happy

'Zhangsan is very happy, and Lisi is even happier.'

b. Zhangsan bi Lisi geng kaixin.

Zhangsan than Lisi GENG happy

'Zhangsan is even happier than Lisi.'

On one hand, in a presupposition comparative like (56a) (i.e., the geng 'GENG' clausal comparative), the degree adverb hen 'HEN' in the standard clause provides a difference degree interval as the standard of comparison at the syntactic level, and causes the comparative morpheme geng 'GENG' to require the other argument which it takes to be a difference degree interval, too. Among these two difference degree intervals, the latter must be greater than the former.

\footnotetext{
${ }^{14}$ The purpose of my dichotomizing Chinese comparatives is to show how particular the Chinese geng 'GENG' clausal comparative is within a larger system of Chinese comparatives, especially from the semantic properties of difference comparison and presupposition as well as its multiclausal syntactic structure. So, it will not have much impact on the dichotomy I propose here even if Lin's (2009) dyadic argument comparison analysis on the Chinese $b i$ 'than' comparative is challenged.
} 
Moreover, the presupposition requirement of the morpheme geng 'GENG' further requires both Zhangsan and Lisi to be happy.

On the other hand, in a presupposition comparative like (56b), the marker $b i$ 'than' introduces the individual Lisi as the compared 'object'; therefore, what are compared by the comparative morpheme geng 'GENG' at the syntactic level are two individuals (i.e., Zhangsan and Lisi). Assuming Heim's (1985) direct analysis to the semantics of phrasal comparatives, the dimension in (56b), namely happiness, is a function from individuals $x$ to degrees $d$; therefore, the comparative morpheme geng 'GENG' in (56b) has a denotation like (57), in which $x$ and $y$ are individuals, and the meaning of (56b) is equivalent to 'The maximal degree interval denoted by Zhangsan's degree of happiness is greater than the maximal degree interval denoted by Lisi's degree of happiness.'

$$
\lambda \mathrm{x} . \lambda \mathrm{P}_{<\mathrm{d},<\mathrm{e}, \mathrm{t}>>} . \lambda \mathrm{y}\left[\mathrm{\iota}_{\max } \mathrm{d}[\mathrm{P}(\mathrm{d})(\mathrm{y})]>\mathrm{\iota}_{\max } \mathrm{d}[\mathrm{P}(\mathrm{d})(\mathrm{x})]\right] \wedge
$$

the properties predicated of $x$ and $y$ are true in the absolute sense

In addition, the presupposition characteristic of the morpheme geng 'GENG' further requires both Zhangsan and Lisi to be happy. ${ }^{15}$

In contrast with the presupposition comparative, comparatives like $(58 \mathrm{a}, \mathrm{b})$, which do not contain the comparative morpheme geng 'GENG', belong to the non-presupposition comparative and contain the covert comparative morpheme gers.

(58) a. Zhangsan (jintian) bi Lisi (zuotian) geng kaixin.

Zhangsan today than Lisi yesterday happy

'Zhangsan (today) is happier than Lisi was yesterday, but it is not necessary

for both of them to be happy.'

b. Zhangsan han Lisi, shei geng gao?

Zhangsan and Lisi who tall

'As for Zhangsan and Lisi, who is taller? It is not necessary for both of them to be tall.'

Semantically, the covert comparative morpheme gers simply denotes a greater-than relation, and takes as arguments the compared object (i.e., the individual Lisi) introduced by the $b i$ 'than phrase and its correspondent in the main clause (i.e., the individual Zhangsan), but does not presuppose that the properties predicated of the compared 'objects' are true in the absolute sense. So the covert comparative morpheme seng in $(58 \mathrm{a}, \mathrm{b})$ has a denotation like (59), in which $x$ and $y$ are individuals and, assuming Heim's (1985) direct analysis to the semantics of phrasal comparatives, they are mapped onto two absolute degree intervals by the dimension function.

$$
\lambda x . \lambda P_{<d,<e, t>>} . \lambda y\left[\iota_{\max } d[P(d)(y)]>\iota_{\max } d[P(d)(x)]\right]
$$

\footnotetext{
${ }^{15}$ Assuming this way of classifying Chinese comparatives, I would say that example (1d), repeated as (i), is the reduced form of either (1b) or (1c), repeated as (ii) and (iii), respectively.

(i) Zhangsan geng kaixin.

Zhangsan GENG happy

'Zhangsan is even happier than somebody is, and both Zhangsan and that person are happy.'

(ii) Zhangsan (jintian) (zai jia li) bi Lisi (zuotian) (zai xuexiao) geng

Zhangsan today at home inside than Lisi yesterday at school GENG

kaixin.

happy

'Zhangsan (today) is even happier (at home) than Lisi was (in school) (yesterday), and both of them are happy.'

(iii) Zhangsan hen kaixin, Lisi geng kaixin.

Zhangsan HEN happy Lisi GENG happy

'Zhangsan is very happy, and Lisi is even happier than he is.'

In other words, examples like (i) are ambiguous between a reading of comparing two difference degree intervals and a reading of comparing two absolute measures of two objects along some dimension. Thus, the actual meaning of (i) depends on what type of 'standard of comparison' the discourse provides.
} 
Hence, what are compared at the syntactic level in a non-presupposition comparative like (58a,b) are two individuals; but what are compared at the semantic level are two corresponding absolute degree intervals. $^{16}$

\section{Implicational parameters of comparison}

Taking as fundamental, my study on the syntax and semantics of the Chinese geng 'GENG' clausal comparative, in this section, I discuss the parameters of comparison across languages implied by my study on the syntax and semantics of the Chinese geng 'GENG' clausal comparative. As I have pointed out, the Chinese geng 'GENG' clausal comparative, on one hand, allows both attributive comparison and comparison between quantities of different sorts of stuff; on the other hand, either the standard clause or the comparee clause of the geng 'GENG' clausal comparative can be embedded in a syntactic island. So it is not implausible for us to say that the Chinese geng 'GENG' clausal comparative involves degree comparison but no degree operator movement at the syntactic level. These characteristics are illustrated by $(60 \mathrm{a}-\mathrm{c})$, respectively.

(60) a. Zhangsan mai-le hen duo shu, Lisi mai-le geng duo shu.

Zhangsan buy-ASP HEN many book Lisi buy-ASP GENG many book

'Zhangsan bought many books, and Lisi bought even more books than Zhangsan bought.'

b. Zhe-duo hua, hua hen hong, yezi geng lü.

This-CL flower flower HEN red leaf GENG green

'As for this flower, the flower is red, but the leaf is even greener than the flower is red.'

c. [s [NP [s Zhe-duo hua hen hong de] shuofa] guran mei cuo], danshi

This-CL flower very red DE statement of-course not wrong but

wo xiang zhidao [CP yezi shifou geng lü].

I want know leaf whether GENG green

'The statement that this flower is very red of course is true, but I wonder

whether the leaf is even greener than the flower is red.'

\footnotetext{
${ }^{16}$ Since the Chinese geng 'GENG' clausal comparative not only allows degree comparison but also involves presupposition necessarily, one anonymous reviewer wonders why the geng 'GENG' clausal comparative clusters together the properties of 'degree comparison' and 'presupposition' in this way. As I have argued, the comparative morpheme geng 'GENG' takes two arguments and requires one of them to be greater than the other along some dimension. The type of arguments which the comparative morpheme geng 'GENG' takes at the syntactic level depends on whether the compared 'object' is introduced by a $b i$ 'than' phrase or by the degree adverb contained in the standard clause of the geng 'GENG' clausal comparative. And it is the 'difference degree interval' component of the semantics of the degree adverb contained in the standard clause that is highlighted and selected as the standard of comparison. As Liu (2010) argues, in Chinese a predicative gradable adjective must appear in a complex form (e.g., a form with adverbs of degree) unless it occurs in a predicate-accessible operator ${ }_{\text {[-wh] }}$ domain, where the occurrence of the covert positive morpheme is licensed. This specific characteristic of the Chinese predicative gradable adjective guarantees that the predicative gradable adjective in the standard clause of the geng 'GENG' clausal comparative is always modified by a degree adverb. This degree adverb then saturates one of the two arguments of the comparative morpheme geng 'GENG' by the 'difference degree interval' component of its semantics. In addition, the semantic meaning of the degree adverb geng 'GENG' (i.e., even more) further requires the properties predicated of the compared 'objects' to be true in the absolute sense. In other words, the cluster of 'degree comparison' and 'presupposition' in the Chinese geng 'GENG' clausal comparative in fact is a result derived from the interaction between the specific property of the Chinese predicative gradable adjective (i.e., a predicative gradable adjective must be modified by a degree adverb) and the semantic meaning of the degree adverb geng 'GENG' (i.e., even more). In this way, the cluster of 'degree comparison' and 'presupposition' in the Chinese geng 'GENG' clausal comparative gets a principled explanation. However, the covert comparative morpheme geng occurs only in comparatives where the standard of comparison is introduced by the $b i$ 'than' phrase. Since the marker $b i$ 'than' cannot takes a clausal complement syntactically, degree comparison (which is possible only if a gradable adjectival predicate is involved) can never be allowed in a comparative construction containing the covert comparative morpheme. Hence, the distribution of the covert comparative morpheme $\&$ eng $\&$ restricted to comparative constructions involving the individual (or phrasal) comparison, as the ungrammaticality of (i) shows.
}

(i) *Zhangsan hen gao, Lisi geng gao.

Zhangsan HEN tall, Lisi tall 
Among these three examples, the grammaticality of $(60 \mathrm{a}, \mathrm{b})$, in particular, is reminiscent of Beck et al.'s (2004:325) Degree Abstraction Parameter, as stated in (61).

Degree Abstraction Parameter (DAP)

A language \{does, does not have binding of degree variables in the syntax.

As Beck et al. (2004) argue, the availability of degree abstraction would allow the generation of attributive degree binding structures and subdeletion structures; that is, the well-formedness of $(60 \mathrm{a}, \mathrm{b})$ implies that the Chinese geng 'GENG' clausal comparative has binding of degree variables in syntax. However, this implication is immediately challenged by the grammaticality of $(60 \mathrm{c})$, which does not show the negative island effect.

At this point, we seem to have reached an impasse; however, the well-formedness of (60c) implies that Beck et al.'s (2004) Degree Abstraction Parameter can be maintained if the following sub-parameter of comparison for languages with degree abstraction is proposed:

\section{Movement versus Non-Movement Parameter in Degree Abstraction}

The binding relation between the operator and the degree variable $\{$ is, is not $\}$ a movement one.

In other words, languages with degree comparison in syntax can be further divided into two subtypes, depending on how the degree variable is bound. One is represented by languages like English, in which the degree variable is bound by the moved compared constituent. According to Kennedy (1999, 2001a), in English clausal comparatives the degree morpheme that heads the compared constituent and the head of the comparative can be assigned the interpretations in $(63 \mathrm{a}, \mathrm{b})$, respectively, where $G$ is a function from objects to degrees, $Q$ is a function from properties to truth values (the semantic value of a clausal constituent with an extracted DegP), and max is a maximality operator that returns the maximal element of an ordered set of objects (Bartsch and Vennemaun, 1973; von Stechow, 1984).

$$
\begin{array}{ll}
\text { a. } & \text { Deg }=\lambda G \lambda Q . \max \{d \mid Q(\lambda x . G(x) \geq d)\} \\
\text { b. } & \text { er/more }=\lambda G \lambda d \lambda x \cdot G(x)>d
\end{array}
$$

Since the comparative clause supplies the 'standard of comparison' argument for the comparative morpheme -er, which establishes a relation between two degrees, we expect the interpretation ultimately assigned to (64a) to be truthconditionally equivalent to the representation given in (64b).

(64) a. Michael's hands are wider than [CP [DegP Deg wide] my feet are [Degp-Deg wide]].

b. ZERO(wide(michael's hands) $\left.-d_{\text {s(the width of human hands })}\right)>$

$\operatorname{ZERO}\left(\max \{d \mid\right.$ wide $($ my feet $\left.)\}-d_{s(\text { the width of human feet })}\right)$

With this analysis, the compared constituent in (64a) (i.e., [DegP Deg wide]) must move at LF and take scope over the rest of the clause to generate the right interpretation of the comparative clause because the quantificational force of the comparative clause (i.e., the maximality operator) is introduced by the degree morphology on the compared constituent rather than by a higher operator (Baker, 1970).

The other subtype is one in which the in situ degree variable is spelled out as a degree adverb and is unselectively bound by an operator base-generated in $[\mathrm{Spec}, \mathrm{CP}]$ of the standard clause or of the clause that contains the standard clause but is directly dominated by the whole construction. For example, in the Chinese geng 'GENG' clausal comparative, the operator that unselectively binds the degree variable is base-generated in [Spec, $\mathrm{CP}]$ of the standard clause or of the clause that contains the standard clause but is directly dominated by the whole construction, as shown by (65a,b), respectively (Huang, 1982; Tsai, 1994; Tsai, 1999). ${ }^{17}$

\footnotetext{
${ }^{17}$ Behind Tsai's (1999:61) analysis to $w h$-movement in Chinese is that only nouns, in contrast with adverbs that are intrinsic operators and must move to create variables, may enter into unselective binding because they are the sole providers of non-pronominal variables. This might prompt us to assume
} 
(65) a. [[CP Op $\mathrm{p}_{\mathrm{i}}\left[\mathrm{Zhangsan} \mathrm{hen}_{\mathrm{i}}\right.$ gao]] [Lisi geng gao]].

Zhangsan very tall Lisi GENG tall

'Zhangsan is tall, and Lisi is even taller.'

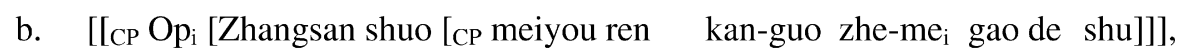

Zhangsan say no people see-ASP this-way tall DE tree

danshi [wo zhidao [Lisi kan-guo geng gao de shu]]]

but I know Lisi see-ASP GENG tall DE tree

'Zhangsan said that nobody saw a tree of that height, but I know that Lisi

saw a tree even taller.'

As I have argued, in the standard clause of a Chinese geng 'GENG' clausal comparative like (65a), the degree adverb hen 'HEN' not only requires the degree interval denoted by Zhangsan's height (i.e., tall(zs)) to be greater than the degree interval denoted by the contextually determined standard height of human beings (i.e., $\mathrm{d}_{s(\text { tall })}$ ), but also requires the difference degree interval between these two degree intervals (i.e., ZERO $\left.\left(\operatorname{tall}(z s)-\mathrm{d}_{s(\text { tall })}\right)\right)$ to be significant, as (66) shows.

$$
\operatorname{tall}(z s)>\mathrm{d}_{s(\text { tall })} \wedge \operatorname{ZERO}\left(\operatorname{tall}(z s)-\mathrm{d}_{s(\text { tall })}\right)>0 \wedge \operatorname{ZERO}\left(\operatorname{tall}(z s)-\mathrm{d}_{s(\text { tall })}\right) \text { is significant }
$$

This 'difference degree interval' component of the semantics of the degree morpheme hen 'HEN' is further highlighted and selected as the standard of comparison by the comparative morpheme geng 'GENG' in the Chinese geng 'GENG' clausal comparative. To make the comparison possible, a correspondent difference degree interval greater than the one provided by the standard clause must be generated in the comparee clause. So, the morpheme geng 'GENG' in the comparee clause of (65a) not only requires the degree interval denoted by Lisi's height (i.e., tall $(l s))$ to be greater than the degree interval denoted by the contextually determined standard height of human beings (i.e., $\mathrm{d}_{s(t a l l)}$ ), but also requires the difference degree interval between these two degree intervals to be significant, as (67) shows.

$$
\operatorname{tall}(l s)>\mathrm{d}_{s(\text { tall })} \wedge \operatorname{ZERO}\left(\operatorname{tall}(l s)-\mathrm{d}_{s(\text { tall })}\right)>0 \wedge \operatorname{ZERO}\left(\operatorname{tall}(l s)-\mathrm{d}_{s(\text { tall })}\right) \text { is significant }
$$

In addition, the comparative morpheme geng 'GENG' further requires the difference degree interval provided by the comparee clause to be greater than the difference degree interval provided by the standard clause. So example (67a) can be assigned an interpretation like (68).

$$
\begin{aligned}
& \operatorname{tall}(z s)>\mathrm{d}_{s(\text { tall })} \wedge \operatorname{ZERO}\left(\operatorname{tall}(z s)-\mathrm{d}_{s(\text { tall })}\right)>0 \wedge \operatorname{ZERO}\left(\operatorname{tall}(z s)-\mathrm{d}_{s(\text { tall })}\right) \text { is significant } \wedge \\
& \operatorname{tall}(l s)>\mathrm{d}_{s(\text { tall })} \wedge \mathrm{ZERO}\left(\text { tall }(l s)-\mathrm{d}_{s(\text { tall })}\right)>0 \wedge \operatorname{ZERO}\left(\text { tall }(l s)-\mathrm{d}_{s(\text { tall })}\right) \text { is significant } \wedge \\
& \operatorname{ZERO}\left(\operatorname{tall}(l s)-\mathrm{d}_{s(\text { tall })}\right)>\operatorname{ZERO}\left(\operatorname{tall}(l s)-\mathrm{d}_{s(\text { tall })}\right)
\end{aligned}
$$

that the degree variable bound by the base-generated operator in the Chinese geng 'GENG' clausal comparative is a noun. This assumption in fact is not impossible. Izvorski (1995) argues for a movement account in which the terms targeted by movement in the English CSD (and possibly CD as well) construction are the amount adjuncts in what quantity and to what degree, as shown by (i)-(ii), rather than the degree heads how (many/much) in (iii)-(iv).

(i) In what quantity does Dennis have tattoos?

(ii) To what degree were the shapes thick?

(iii) *How many does Dennis have [DP tattoos]]?

(iv) $*\left[{ }_{\mathrm{CP}}\right.$ How are the shapes [DegP thick]]?

Further evidence for the assumption that the degree variable in the Chinese geng 'GENG' clausal comparative is a noun comes from Huang's (1982) treatment of the non-sensitivity to island effects shown by (zai) nali '(at) where' and (zai) shenmeshihou '(at) when' in Chinese. As Huang (1982) argues, (zai) nali 'at where' and (zai) shenmeshihou 'at when', though always analyzed as adjuncts, actually are nouns. So, it is not implausible for us to say that the degree variable in the Chinese geng 'GENG' clausal comparative, though it looks like an adverbial adjunct, in fact can be considered a noun. 
Since the operator based-generated in [Spec, $\mathrm{CP}]$ of the standard clause unselectively binds the degree adverb hen 'HEN', it is not unreasonable for us to say that the degree operator (i.e., Op) 'inherits' all the semantic properties of the degree adverb hen 'HEN'. As a result, the 'exceed the standard' part of the meaning of the geng 'GENG' clausal comparative (65a) as well as the presupposition that both Zhangsan and Lisi are tall is naturally derived under my analysis. ${ }^{18}$

Put simply, although English clausal comparatives and the Chinese geng 'GENG' clausal comparative both involve degree comparison in syntax, they differ from each other in the way of binding the degree variable. The sub-parameter proposed (i.e., Movement versus Non-Movement Parameter in Degree Abstraction) further explains why the proper English translation of the Chinese geng 'GENG' clausal comparative (28b), repeated as $(69 a)$, is $(69 \mathrm{~b})$, in which the standard of comparison introduced by the than phrase (i.e., the degree operator $\mathrm{Op}_{\mathrm{i}}$ ) must be local to the head of the comparative (i.e., blacker), but this kind of local relation is not necessarily required in the Chinese geng 'GENG' clausal comparative, as shown by the contrast between (69a) and (69b). ${ }^{19}$

(69) a. [s Opp [NP [s Zhao Min pifu hen ${ }_{i}$ bai de] shuofa] guran mei cuo],

Zhao Min skin HEN white DE statement of-course not wrong

danshi wo xiang zhidao [cP toufa shifou geng hei].

but I wonder know hair whether GENG black

b. The statement that the skin of Zhao Min is very white is absolutely true,

but I wonder whether her hair is even blacker than [ ${ }_{\mathrm{CP}} \mathrm{Op}$ [ [her skin is $\mathrm{t}_{\mathrm{i}}$-white]].

Thus far, the discussion amounts to saying that Chinese does have degree comparison in syntax, contra the claim made by Xiang (2005), Kennedy (2007), and Lin (2009) that Chinese has only individual comparison in syntax. So we might want to say that both Chinese and English have individual and degree comparison in syntax. However, English uses the same type of comparative construction, namely the than particle comparative, to express degree and individual comparison, depending on whether the complement of than is a clause or a noun phrase, whereas Chinese uses the geng 'GENG' clausal comparative to express degree comparison but the bi 'than' comparative to express individual comparison at the syntactic level.

\footnotetext{
${ }^{18}$ One anonymous reviewer points out that if Zhangsan hen gao 'Zhangsan HEN tall' has an analysis as a degree and if Chinese has degree comparison, then why is (i) ungrammatical?

(i) * Lisi bi $\left[\mathrm{Op}_{\mathrm{i}}\left[\right.\right.$ Zhangsan hen $\mathrm{Z}_{\mathrm{i}}$ gao $]$ gao.

Lisi than Op Zhangsan HEN tall tall

'Lisi is taller than Zhangsan is.'

The ungrammaticality of examples like (i) in fact is not related to my proposal that the Chinese geng 'GENG' clausal comparative involves degree comparison in syntax. As Beck et al. (2004), Kennedy (2005, 2007), Xiang (2005) and Lin (2009) argue, the Chinese bi 'than' comparative can only be analyzed as a phrasal comparative; in other words, the marker $b i$ 'than' cannot take a clausal complement. So, (i), in which the marker $b i$ 'than' takes a clause as complement, is ungrammatical.

${ }^{19}$ Given that the modified English translation for (69a) provided by one anonymous reviewer (i.e., (i)) is grammatical and does not show island sensitivity, the reviewer suggests that the proposed parameter (i.e., the binding relation between the degree operator and the degree variable is achieved via movement or not) might not differ according to language but rather according to the syntax of the construction.

(i) The statement that the skin of Zhao Min is very white is absolutely true, but I wonder whether her hair is even blacker.

However, I argue that this alternative cannot hold because example (i) can be considered as one involving an elided than phrase that is local to the head of the comparative (i.e., blacker), as (ii) shows.

(ii) The statement that the skin of Zhao Min is very white is absolutely true, but I wonder whether her hair is even blacker

But (69a) cannot be analyzed as one containing an elided $b i$ 'than' phrase that is local to the head of the comparative (i.e., geng hei 'GENG black'), as the ungrammaticality of (iii) illustrates.

(iii) *[s [Np [s Zhao Min pifu hen bai de] shuofa] guran mei cuo], danshi

Zhao Min skin HEN white DE statement of-course not wrong but

wo xiang zhidao [CP toufa shifou [bi pifu hen bai] geng hei].

I wonder know hair whether than skin HEN white GENG black

In other words, (69a) and the English example (i) cannot be considered as the same type of construction. So the alternative suggested by the reviewer cannot be maintained.
} 


\section{Concluding remarks}

Contra Kennedy (2005, 2007), Xiang (2005), and Lin (2009), based on the syntax and semantics of the Chinese geng 'GENG' clausal comparative, I argued that Chinese does have degree comparison in syntax. This claim not only raised an intra-language question but also an inter-language question: the former is how the Chinese geng 'GENG' clausal comparative fits into a larger system of Chinese comparatives, which led me to dichotomize Chinese comparatives into presupposition comparatives like $(29 \mathrm{~b}, \mathrm{c})$ on one hand, and non-presupposition comparative like (29a) on the other. The inter-language one is whether the Degree Abstraction Parameter proposed by Beck et al. (2004) can be maintained. I suggested that the Degree Abstraction Parameter can be maintained if languages involving degree comparison in syntax are further divided into two types depending on how the degree variable is bound.

\section{Acknowledgements}

Earlier working versions and portions of this article were presented in my 2008 fall Seminar in Syntax at National Chiao Tung University (Taiwan), the Sixth Workshop on Formal Syntax and Semantics at National Taiwan Normal University, and the Seventeenth Annual Conference of the International Association of Chinese Linguistics at Centre de Recherches Linguistiques sur l'Asie Orientale in Paris. I thank the audiences at these occasions for their valuable comments and useful suggestions. Of the many people who have contributed to the improvement of this article, I am particularly grateful to Yi-Hsun Chen, Hui-Yu Huang, James Huang, Cheng-Chuen Kuo, Chin-Man Kuo, James Tai, Hui-Chin Tsai, Ting-Chi Wei, Ching-Yu, Yang, and especially Jo-Wang Lin for their penetrating and rigorous comments as well as constructive suggestions. I am also indebted to Terri Griffith for her editorial help and the anonymous reviewers for their suggestions that helped me greatly in shaping both the content and the exposition of this article. Added to these, I gratefully acknowledge the research grant (NSC-98-2410-H-009-039) from National Science Council in Taiwan. Finally, any errors or inconsistencies that have persisted, of course, are my responsibility.

\section{Appendix A. Supplementary data}

Supplementary data associated with this article can be found, in the online version, at doi:10.1016/ j.lingua.2009.09.005.

\section{References}

Baker, C.L., 1970. Notes on the description of English questions. Foundations of Language 6, 197-219.

Bartsch, R., Vennemaun, T., 1973. Semantic Structures: A Study in the Relation between Syntax and Semantics. Athaenum Verlag, Frankfurt.

Beck, S., Oda, T., Sugisaki, K., 2004. Parametric variation in the semantics of comparison: Japanese vs. English. Journal of East Asian Linguistics 13 (4), 289-344.

Bierwisch, M., 1987. The semantics of gradation. In: Bierwisch, M., Lang, E. (Eds.), Dimensional Adjectives. Springer-Verlag, Berlin, pp. 71-262. Chao, Y.R., 1968. A Grammar of Spoken Chinese. University of California Press, Berkeley.

Chomsky, N., 1977. On wh-movement. In: Culicover, P., Wasow, T., Akmajian, A. (Eds.), Formal Syntax. Academic Press, New York, pp. 71-132. Cresswell, M.J., 1976. Adverbial Modification: Interval Semantics and Its Rivals [Studies in Linguistics and Philosophy 28]. Reidel, Dordrecht. Erlewine, M., 2007. A new syntax-semantics for the Mandarin bi comparative. Master Thesis. University of Chicago.

Fu, Y.C., 1977. Comparative structures in English and Mandarin Chinese. Doctoral Dissertation. University of Michigan.

Graff, D., 2000. Shifting sands: an interest-relative theory of vagueness. Philosophical Topics 28 (1), 45-81.

Hale, A., 1970. Conditions on English comparative clause pairings. In: Jacobs, R., Rosenbaum, P. (Eds.), Readings in English Transformational Grammar. Ginn, Waltham, MA, pp. 30-55.

Hazout, I., 1995. Comparative ellipsis and logical form. Natural Language and Linguistic Theory 13 (1), 1-37.

Heim, I., 1985. Notes on Comparatives and Related Matters. Ms. University of Texas, Austin.

Hellan, L., 1981. Towards an Integrated Analysis of Comparative. Narr, Tübingen.

Huang, C.T.J., 1982. Logical relations in Chinese and the theory of grammar. Doctoral Dissertation. MIT.

Izvorski, R., 1995. A solution to the subcomparative paradox. In: Camacho, J., Chouieri, Watanabe, M. (Eds.), The Proceedings of the Fourteenth West Coast Conference on Formal Linguistics. CSLI Publications, Stanford, CA, pp. 203-219.

Kennedy, C., 1999. Projecting the Adjective: The Syntax and Semantics of Gradability and Comparison. Garland, New York.

Kennedy, C., 2001a. Polar opposition and the ontology of 'degrees'. Linguistics and Philosophy 24 (1), 33-70.

Kennedy, C., 2001b. Comparative deletion and optimality in syntax. Natural Language and Linguistic Theory 20 (3), $553-621$.

Kennedy, C., 2005. Parameters of Comparison. Ms. University of Chicago.

Kennedy, C., 2007. Modes of comparison. The Proceedings from the Annual Meeting of the Chicago Linguistic Society 43 (1), $141-165$. 
Kennedy, C., McNally, L., 2005. Scale structure and the semantic typology of gradable predicates. Language 81 (2), $345-381$.

Ladusaw, W., 1986. Principles of semantic filtering. In: Dalrymple, D., et al. (Eds.), The Papers from the Fifth Western Conference on Formal Linguistics. Stanford Linguistics Association, Stanford, CA, pp. 129-141.

Landman, F., 1991. Structures for Semantics. Kluwer, Dordrecht.

Li, C.N., Thompson, S.A., 1981. Mandarin Chinese: A Functional Reference Grammar. University of California Press, Berkeley.

Lin, J.W., 2009. Chinese comparatives and their implicational parameters. Natural Language Semantics 17 (1), 1-27.

Linebarger, M., 1980. The grammar of negative polarity. Doctoral Dissertation. MIT.

Liu, C.S.L., 1996. A note on Chinese comparatives. Studies in the Linguistic Sciences 26 (1/2), 215-235.

Liu, C.S.L., 2007. The weak comparative morpheme in Mandarin Chinese. Concentric: Studies in Linguistics 33 (2), 53-89.

Liu, C.S.L., 2010. The positive morpheme in Chinese and the adjectival structure. Lingua 120, 1502-1515.

Liu, Y., 2004. Xiandai Hanyu Bijiao Fanchou de Yuyi Renzhi Jichu [The Semantic Cognitive Basis of Comparatives in Modern Chinese]. Xuelin Chubanshe, Shanghai.

Liu, Y.H., Pan, W.Y., Gu, H., 2004. Shiyong Xiandai Hanyu Yufa [Modern Chinese Grammar]. Shangwu Yinshuguan, Beijing.

Lu, J.M., Ma, Z., 1999. Xiandai Hanyu Xuci Sanlun [Essays on Functional Words in Modern Chinese]. Shangwu Yinshuguan, Beijing.

Ma, Q.Z., 1992. Han Chengdu Buyu de Shubu Jiegou - Hanyu Dongci han Dongcixing Jiegou [The Predicate-Complement Structure with Degree Complements: Verbs and Verbal Structures in Chinese]. Beijing Yuyan Xueyuan Chubanshe, Beijing.

Paul, W., 1993. A non-deletion account of the comparative construction in Mandarin Chinese. Cahiers de Linguistique Asie Orientale 93 (1), 9-29.

Ross, J.R., 1967. Constraints on variables in syntax. Doctoral Dissertation. MIT.

Rullmann, H., 1995. Maximality in the semantics of WH-constructions. Doctoral Dissertation. University of Massachusetts at Amherst.

Schwarzschild, R., Wilkinson, K., 2002. Quantifiers in comparatives: a semantics of degree based on intervals. Natural Language Semantics 10 (1), $1-41$.

Seuren, P.A.M., 1978. The structure and selection of positive and negative gradable adjectives. In: Farkas, D., Jacobson, W., Todrys, K. (Eds.), The Papers from the Parasession on the Lexicon of the Chicago Linguistic Society, vol. 14. University of Chicago, Chicago, IL, pp. 336-346.

Shi, D.X., 2001. The nature of Chinese comparatives. In: Pan, H.H. (Ed.), Studies in Chinese Linguistics, vol. II. Linguistic Society of Hong Kong, Hong Kong, pp. 137-158.

Stassen, L., 1985. Comparison and Universal Grammar. Basil Blackwell, Oxford.

Tsai, W.T.D., 1994. On economizing the theory of A-Bar dependencies. Doctoral Dissertation. MIT.

Tsai, W.T.D., 1999. On lexical courtesy. Journal of East Asian Linguistics 8 (1), 39-73.

Tsao, F.F., 1989. Comparison in Chinese: a topic-comment approach. Tsing Hua Journal of Chinese Studies 19, $151-189$.

von Stechow, A., 1984. Comparing semantic theories of comparison. Journal of Semantics 3 (1), 1-77.

Williams, E., 1977. Discourse and logical form. Linguistic Inquiry 8 (1), 101-139.

Xiang, M., 2005. Some topics in comparative constructions. Doctoral Dissertation. Michigan State University.

Xing, F.Y., 2001. In: Xiao, G.Z. (Ed.), Ershi Shiji Xiandai Hanyu Yufa Ba Da Jia: Xing Fu-Yi Xuanji [The Eight Major Syntacticans of Modern Chinese Syntax in the Twentieth Century: The Selected Papers by Xing Fu-Yi]. Dongbei Shifan Daxue, Changchun.

Xing, F.Y., 2004. Hanyu Yufa Sanbai Wen [Three Hundred Questions for Chinese Syntax]. Shangwu Yinshuguan, Beijing.

Xu, G.P., 2007. Xiandai Hanyu Chabi Fanchou Yanjiu [A Study of Superiority Comparatives in Modern Chinese]. Xuelin Publishers, Shanghai. Zhang, Y.J., 2002. Fuci yu Xianding Miaozhuang Gongneng [Adverbs and the Function of Attributive Modifiers]. Anhui Jiaoyu Chubanshe, Hefei. 